\title{
Microalgae for biodiesel production and other applications: A review
}

\author{
Teresa M. Mata, António A. Martins, Nidia. S. Caetano
}

A B S T R A C T

Sustainable production of renewable energy is being hotly debated globally since it is increasingly understood that first generation biofuels, primarily produced from food crops and mostly oil seeds are limited in their ability to achieve targets for biofuel production, climate change mitigation and economic growth. These concerns have increased the interest in developing second generation biofuels produced from non-food feedstocks such as microalgae, which potentially offer greatest opportunities in the longer term. This paper reviews the current status of microalgae use for biodiesel production, including their cultivation, harvesting, and processing. The microalgae species most used for biodiesel production are presented and their main advantages described in comparison with other available biodiesel feedstocks. The various aspects associated with the design of microalgae production units are described, giving an overview of the current state of development of algae cultivation systems (photo-bioreactors and open ponds). Other potential applications and products from microalgae are also presented such as for biological sequestration of $\mathrm{CO}_{2}$, wastewater treatment, in human health, as food additive, and for aquaculture.

Keywords:

Microalgae

Biodiesel

Photo-bioreactors

Open ponds

Environmental applications

High-value chemical compounds 


\section{Introduction}

The transportation and energy sectors are the major anthropogenic sources, responsible in European Union (EU) for more than $20 \%$ and $60 \%$ of greenhouse gas (GHG) emissions, respectively [1]. Agriculture is the third largest anthropogenic source, representing about $9 \%$ of GHG emissions, where the most important gases are nitrous oxide $\left(\mathrm{N}_{2} \mathrm{O}\right)$ and methane $\left(\mathrm{CH}_{4}\right)$ [2]. It is expected that with the development of new growing economies, such as India and China, the global consumption of energy will raise and lead to more environmental damage [3].

GHG contributes not only to global warming (GW) but also to other impacts on the environment and human life. Oceans absorb approximately one-third of the $\mathrm{CO}_{2}$ emitted each year by human activities and as its levels increase in the atmosphere, the amount dissolved in oceans will also increase turning the water $\mathrm{pH}$ gradually to more acidic. This $\mathrm{pH}$ decrease may cause the quick loss of coral reefs and of marine ecosystem biodiversity with huge implications in ocean life and consequently in earth life [4].

As GW is a problem affecting different aspects of human life and the global environment, not only a single but a host of solutions is needed to address it. One side of the problem concerns the reduction of crude oil reserves and difficulties in their extraction and processing, leading to an increase of its cost [5]. This situation is particularly acute in the transportation sector, where currently there are no relevant alternatives to fossil fuels.

To find clean and renewable energy sources ranks as one of the most challenging problems facing mankind in the medium to long term. The associated issues are intimately connected with economic development and prosperity, quality of life, global stability, and require from all stakeholders tough decisions and long term strategies. For example, many countries and regions around the world established targets for $\mathrm{CO}_{2}$ reduction in order to meet the sustainability goals agreed under the Kyoto Protocol.

Presently many options are being studied and implemented in practice, with different degrees of success, and in different phases of study and implementation. Examples include solar energy, either thermal or photovoltaic, hydroelectric, geothermal, wind, biofuels, and carbon sequestration, among others $[6,7]$. Each one has its own advantages and problems and, depending on the area of application, different options will be better suited. One important goal is to take measures for transportation emissions reduction, such as the gradual replacement of fossil fuels by renewable energy sources, where biofuels are seen as real contributors to reach those goals, particularly in the short term.

Biofuels production is expected to offer new opportunities to diversify income and fuel supply sources, to promote employment in rural areas, to develop long term replacement of fossil fuels, and to reduce GHG emissions, boosting the decarbonisation of transportation fuels and increasing the security of energy supply.

The most common biofuels are biodiesel and bio-ethanol, which can replace diesel and gasoline, respectively, in today cars with little or none modifications of vehicle engines. They are mainly produced from biomass or renewable energy sources and contribute to lower combustion emissions than fossil fuels per equivalent power output. They can be produced using existing technologies and be distributed through the available distribution system. For this reason biofuels are currently pursued as a fuel alternative that can be easily applied until other options harder to implement, such as hydrogen, are available.

Although biofuels are still more expensive than fossil fuels their production is increasing in countries around the world. Encouraged by policy measures and biofuels targets for transport, its global production is estimated to be over 35 billion liters [8].

The main alternative to diesel fuel in EU is biodiesel, representing $82 \%$ of total biofuels production [9] and is still growing in Europe, Brazil, and United States, based on political and economic objectives.

Biodiesel is produced from vegetable oils (edible or non-edible) or animal fats. Since vegetable oils may also be used for human consumption, it can lead to an increase in price of food-grade oils, causing the cost of biodiesel to increase and preventing its usage, even if it has advantages comparing with diesel fuel.

The potential market for biodiesel far surpasses the availability of plant oils not designated for other markets. For example, to fulfill a $10 \%$ target in EU from domestic production, the actual feedstocks supply is not enough to meet the current demand and the land requirements for biofuels production, would be more than the potential available arable land for bio-energy crops [10]. The extensive plantation and pressure for land use change and increase of cultivated fields may lead to land competition and biodiversity loss, due to the cutting of existing forests and the utilization of ecological importance areas [11]. Biodiesel may also be disadvantageous when replacing crops used for human consumption or if its feedstocks are cultivated in forests and other critical habitats with associated biological diversity.

Current policies at regional and national levels and the expected cost and difficulties in obtaining fossil fuels will necessarily lead to an increase in biodiesel production and of other types of renewable energy. To become a more viable alternative fuel and to survive in the market, biodiesel must compete economically with diesel. The end cost of biodiesel mainly depends on the price of the feedstocks that accounts for $60-75 \%$ of the total cost of biodiesel fuel [12].

In order to not compete with edible vegetable oils, the low-cost and profitable biodiesel should be produced from low-cost feedstocks such as non-edible oils, used frying oils, animal fats, soap-stocks, and greases. However the available quantities of waste oils and animal fats are not enough to match the today demands for biodiesel. Thus transition to second generation biofuels, such as microalgae, can also contribute to a reduction in land requirements due to their presumed higher energy yields per hectare as well as to their non-requirement of agricultural land. Additionally, biodiesel needs to have lower environmental impacts and ensure the same level of performance of existing fuels [13].

Albeit the growing interest and fast growth of this area, it is still on its infancy. A large investment in research and development (R\&D) and correct policies and strategies are still needed, for all stages of the biofuels value chain, from raw materials production to delivery and final consumption. Among the various possibilities currently being investigated and implemented at pilot scale or even at industrial scale concerning potential feedstocks, the more interesting ones are microalgae. Besides their cultivation is not directly linked to human consumption, they have low space requirements for its production.

This review focuses its attention on microalgae and how they can be used for biodiesel production. Questions associated with production and processing of microalgae are considered in detail, 
not only those directly related with biofuels production but also the possibilities of combining it with pollution control, in particular with biological sequestration of $\mathrm{CO}_{2}$ emissions and other greenhouse gases, or wastewater treatment. This work starts by describing which microalgae are normally used for the production of biofuels and their main advantages when compared with other available feedstocks. Then, the current status of biodiesel production from microalgae, concerning their growth, harvest, and processing is reviewed. Other potential applications and how to combine them with biodiesel production are also described.

\section{Microalgae for biodiesel production}

\subsection{Viability of microalgae for biodiesel}

\subsubsection{What are microalgae?}

Microalgae are prokaryotic or eukaryotic photosynthetic microorganisms that can grow rapidly and live in harsh conditions due to their unicellular or simple multicellular structure. Examples of prokaryotic microorganisms are Cyanobacteria (Cyanophyceae) and eukaryotic microalgae are for example green algae (Chlorophyta) and diatoms (Bacillariophyta) [14,15]. A more in depth description of microalgae is presented by Richmond [16].

Microalgae are present in all existing earth ecosystems, not just aquatic but also terrestrial, representing a big variety of species living in a wide range of environmental conditions. It is estimated that more than 50,000 species exist, but only a limited number, of around 30,000, have been studied and analyzed [16].

During the past decades extensive collections of microalgae have been created by researchers in different countries. An example is the freshwater microalgae collection of University of Coimbra (Portugal) considered one of the world's largest, having more than 4000 strains and 1000 species. This collection attests to the large variety of different microalgae available to be selected for use in a broad diversity of applications, such as value added products for pharmaceutical purposes, food crops for human consumption and as energy source.

A bit all over the world, other algae collections attest for the interest that algae have risen, for many different production purposes. For example, the collection of the Goettingen University, Germany (SAG), that started in the early 1920s and has about 2213 strains and 1273 species. About $77 \%$ of all the strains in the SAG collection are green algae and about $8 \%$ cyanobacteria (61 genera and 230 strains). Some of them are freshwater red algae and others from saline environments.

The University of Texas Algal Culture Collection is another very well known collection of algae cultures that was founded in 1953. It includes 2300 different strains of freshwater algae (edaphic green algae and cyanobacteria), but includes representatives of most major algal taxa, including many marine macrophytic green and red algae species.

In the Asian continent, the National Institute for Environmental Studies Collection (NIES), in Ibaraki, Japan, holds a collection of about 2150 strains, with around 700 species of different algae. The CSIRO Collection of Living Microalgae (CCLM), in Australia, holds about 800 strains of different algae, including representatives from the majority of classes of marine and some freshwater microalgae, being the majority of the strains isolated from Australian waters.

\subsubsection{Advantages of using microalgae for biodiesel production}

Many research reports and articles described many advantages of using microalgae for biodiesel production in comparison with other available feedstocks [14,15,17,21-27]. From a practical point of view, they are easy to cultivate, can grow with little or even no attention, using water unsuitable for human consumption and easy to obtain nutrients.
Microalgae reproduce themselves using photosynthesis to convert sun energy into chemical energy, completing an entire growth cycle every few days [17]. Moreover they can grow almost anywhere, requiring sunlight and some simple nutrients, although the growth rates can be accelerated by the addition of specific nutrients and sufficient aeration [18-20].

Different microalgae species can be adapted to live in a variety of environmental conditions. Thus, it is possible to find species best suited to local environments or specific growth characteristics, which is not possible to do with other current biodiesel feedstocks (e.g. soybean, rapeseed, sunflower and palm oil).

They have much higher growth rates and productivity when compared to conventional forestry, agricultural crops, and other aquatic plants, requiring much less land area than other biodiesel feedstocks of agricultural origin, up to 49 or 132 times less when compared to rapeseed or soybean crops, for a $30 \%(\mathrm{w} / \mathrm{w})$ of oil content in algae biomass [21]. Therefore, the competition for arable soil with other crops, in particular for human consumption, is greatly reduced.

Microalgae can provide feedstock for several different types of renewable fuels such as biodiesel, methane, hydrogen, ethanol, among others. Algae biodiesel contains no sulfur and performs as well as petroleum diesel, while reducing emissions of particulate matter, $\mathrm{CO}$, hydrocarbons, and $\mathrm{SO}_{x}$. However emissions of $\mathrm{NO}_{x}$ may be higher in some engine types [28].

The utilization of microalgae for biofuels production can also serve other purposes. Some possibilities currently being considered are listed below.

- Removal of $\mathrm{CO}_{2}$ from industrial flue gases by algae bio-fixation [29], reducing the GHG emissions of a company or process while producing biodiesel [30].

- Wastewater treatment by removal of $\mathrm{NH}_{4}{ }^{+}, \mathrm{NO}_{3}{ }^{-}, \mathrm{PO}_{4}{ }^{3-}$, making algae to grow using these water contaminants as nutrients [29].

- After oil extraction the resulting algae biomass can be processed into ethanol, methane, livestock feed, used as organic fertilizer due to its high N:P ratio, or simply burned for energy cogeneration (electricity and heat) [29];

- Combined with their ability to grow under harsher conditions, and their reduced needs for nutrients, they can be grown in areas unsuitable for agricultural purposes independently of the seasonal weather changes, thus not competing for arable land use, and can use wastewaters as the culture medium, not requiring the use of freshwater.

- Depending on the microalgae species other compounds may also be extracted, with valuable applications in different industrial sectors, including a large range of fine chemicals and bulk products, such as fats, polyunsaturated fatty acids, oil, natural dyes, sugars, pigments, antioxidants, high-value bioactive compounds, and other fine chemicals and biomass $[14,15,31]$.

- Because of this variety of high-value biological derivatives, with many possible commercial applications, microalgae can potentially revolutionize a large number of biotechnology areas including biofuels, cosmetics, pharmaceuticals, nutrition and food additives, aquaculture, and pollution prevention $[25,31]$.

\subsubsection{Historic evolution of microalgae production systems}

For the past 50 years, extensive research has been performed on microalgae and how they can be used in a wide variety of processes or to manufacture many practical and economic important products. The first large-scale culture of microalgae started in the early 1960s in Japan by Nihon Chlorella with the culture of Chlorella [32]. The interest in using microalgae for renewable energy increased in 1970s during the first oil crisis [32]. 
The U.S. National Renewable Energy Laboratory (NREL) through the Aquatic Species Program (ASP), launched a specific R\&D Program dedicated to alternative renewable fuels, including biodiesel from microalgae that lasted from 1978 to 1996 [17]. One of its main objectives was to study the biochemistry and physiology of lipid production in oleaginous microalgae. From 1987 to 1990 , an "Outdoor Test Facility" of two $1000 \mathrm{~m}^{2}$ high-rate ponds was operated in Roswell, New Mexico. It was concluded that the use of microalgae for the low-cost production of biodiesel was technically feasible, but still needs considerable long term R\&D to achieve the high productivities required. Other objective of this NREL R\&D program was to produce improved algae strains by looking for genetic variability between algal isolates, attempting to use flow cytometry to screen for naturally occurring high lipid individuals, and exploring algal viruses as potential genetic vectors. However in 1995 the Department of Energy reduced the budget allocated to funding this program and it was discontinued before these experiments could be carried out beyond the preliminary stages [17].

The recent price volatility of crude oil and the expected future price increase, tied with the urge to reduce pollutant emissions and greenhouse gases, have created a new interest in the production of biodiesel using microalgae. For example, several companies were created or have entered this market niche, selling either entire processes or key process units, such as photo-bioreactors with optimized designs to cultivate microalgae for biodiesel production and other applications [33-35]. Torrey [37] presents links to 37 companies that are currently exploring algae as a fuel source.

Nowadays, microalgae are seen as an alternative feedstock for biodiesel production, being the target of a large number of consortiums, private and public organizations' investments in $\mathrm{R} \& \mathrm{D}$, aiming to use the most effective and cheap technology to produce large amounts of oil. They are considered to be a second generation feedstock together with other biomass sources, such as Jatropha, lignocellulosic materials, agricultural residues, and systematically grown energy crops, with high potential yields of biofuels and that are not used as food source for human consumption [36].

Though it is not cost effective yet to compete with fossil diesel without additional support (for example government subsidies) research is being done to turn it economically viable, both in academia and in industry $[35,38,39]$. In a long term, as crude oil reserves diminish and price per barrel increases in a daily basis, other alternatives must become available, and thus, it is now the time to search, develop and implement them.

Recent research efforts have concentrated on applying metabolic engineering and genetic methods to microalgae in order to develop organisms optimized for high productivity and energy

Table 1

Lipid content and productivities of different microalgae species.

\begin{tabular}{|c|c|c|c|c|}
\hline $\begin{array}{l}\text { Marine and freshwater } \\
\text { microalgae species }\end{array}$ & $\begin{array}{l}\text { Lipid content } \\
\text { (\% dry weight biomass) }\end{array}$ & $\begin{array}{l}\text { Lipid } \\
\text { productivity (mg/L/day) }\end{array}$ & $\begin{array}{l}\text { Volumetric productivity } \\
\text { of biomass ( } \mathrm{g} / \mathrm{L} / \text { day) }\end{array}$ & $\begin{array}{l}\text { Areal productivity } \\
\text { of biomass }\left(\mathrm{g} / \mathrm{m}^{2} / \text { day }\right)\end{array}$ \\
\hline Ankistrodesmus sp. & $24.0-31.0$ & - & - & $11.5-17.4$ \\
\hline Botryococcus braunii & $25.0-75.0$ & - & 0.02 & 3.0 \\
\hline Chaetoceros muelleri & 33.6 & 21.8 & 0.07 & - \\
\hline Chaetoceros calcitrans & $14.6-16.4 / 39.8$ & 17.6 & 0.04 & - \\
\hline Chlorella emersonii & $25.0-63.0$ & $10.3-50.0$ & $0.036-0.041$ & $0.91-0.97$ \\
\hline Chlorella protothecoides & $14.6-57.8$ & 1214 & $2.00-7.70$ & - \\
\hline Chlorella sorokiniana & $19.0-22.0$ & 44.7 & $0.23-1.47$ & - \\
\hline Chlorella vulgaris & $5.0-58.0$ & $11.2-40.0$ & $0.02-0.20$ & $0.57-0.95$ \\
\hline Chlorella sp. & $10.0-48.0$ & 42.1 & $0.02-2.5$ & $1.61-16.47 / 25$ \\
\hline Chlorella pyrenoidosa & 2.0 & - & $2.90-3.64$ & $72.5 / 130$ \\
\hline Chlorella & $18.0-57.0$ & 18.7 & - & $3.50-13.90$ \\
\hline Chlorococcum sp. & 19.3 & 53.7 & 0.28 & - \\
\hline Crypthecodinium cohnii & $20.0-51.1$ & - & 10 & - \\
\hline Dunaliella salina & $6.0-25.0$ & 116.0 & $0.22-0.34$ & $1.6-3.5 / 20-38$ \\
\hline Dunaliella primolecta & 23.1 & - & 0.09 & 14 \\
\hline Dunaliella tertiolecta & $16.7-71.0$ & - & 0.12 & - \\
\hline Dunaliella sp. & $17.5-67.0$ & 33.5 & - & - \\
\hline Ellipsoidion sp. & 27.4 & 47.3 & 0.17 & - \\
\hline Euglena gracilis & $14.0-20.0$ & - & 7.70 & - \\
\hline Haematococcus pluvialis & 25.0 & - & $0.05-0.06$ & $10.2-36.4$ \\
\hline Isochrysis galbana & $7.0-40.0$ & - & $0.32-1.60$ & - \\
\hline Isochrysis sp. & $7.1-33$ & 37.8 & $0.08-0.17$ & - \\
\hline Monodus subterraneus & 16.0 & 30.4 & 0.19 & - \\
\hline Monallanthus salina & $20.0-22.0$ & - & 0.08 & 12 \\
\hline Nannochloris sp. & $20.0-56.0$ & $60.9-76.5$ & $0.17-0.51$ & - \\
\hline Nannochloropsis oculata. & $22.7-29.7$ & $84.0-142.0$ & $0.37-0.48$ & - \\
\hline Nannochloropsis sp. & $12.0-53.0$ & $37.6-90.0$ & $0.17-1.43$ & $1.9-5.3$ \\
\hline Neochloris oleoabundans & $29.0-65.0$ & $90.0-134.0$ & - & - \\
\hline Nitzschia sp. & $16.0-47.0$ & & & $8.8-21.6$ \\
\hline Oocystis pusilla & 10.5 & - & - & $40.6-45.8$ \\
\hline Pavlova salina & 30.9 & 49.4 & 0.16 & - \\
\hline Pavlova lutheri & 35.5 & 40.2 & 0.14 & - \\
\hline Phaeodactylum tricornutum & $18.0-57.0$ & 44.8 & $0.003-1.9$ & $2.4-21$ \\
\hline Porphyridium cruentum & $9.0-18.8 / 60.7$ & 34.8 & $0.36-1.50$ & 25 \\
\hline Scenedesmus obliquus & $11.0-55.0$ & - & $0.004-0.74$ & - \\
\hline Scenedesmus quadricauda & $1.9-18.4$ & 35.1 & 0.19 & - \\
\hline Scenedesmus sp. & 19.6-21.1 & $40.8-53.9$ & $0.03-0.26$ & $2.43-13.52$ \\
\hline Skeletonema sp. & $13.3-31.8$ & 27.3 & 0.09 & - \\
\hline Skeletonema costatum & $13.5-51.3$ & 17.4 & 0.08 & - \\
\hline Spirulina platensis & $4.0-16.6$ & - & $0.06-4.3$ & $1.5-14.5 / 24-51$ \\
\hline Spirulina maxima & $4.0-9.0$ & - & $0.21-0.25$ & 25 \\
\hline Thalassiosira pseudonana & 20.6 & 17.4 & 0.08 & - \\
\hline Tetraselmis suecica & $8.5-23.0$ & $27.0-36.4$ & $0.12-0.32$ & 19 \\
\hline Tetraselmis sp. & $12.6-14.7$ & 43.4 & 0.30 & - \\
\hline
\end{tabular}


value, in order to achieve their full processing capabilities [25,31]. Since microalgae represent a much simpler system than plants, usually with no cell differentiation, genetic manipulations to increase its content of higher value compounds is very tempting. Nevertheless, progress in the genetic engineering of algae was extremely slow until recently. Also, these promising advances should be viewed with caution because transgenic algae potentially pose a considerable threat to the ecosystem and thus will most likely be banned from outdoor cultivation systems [40].

\subsubsection{Microalgae lipid content and productivities}

Many microalgae species can be induced to accumulate substantial quantities of lipids [17] thus contributing to a high oil yield. The average lipid content varies between 1 and $70 \%$ but under certain conditions some species can reach $90 \%$ of dry weight $[14,15,21,32]$.

Table 1 presents both lipid content and lipid and biomass productivities of different marine and freshwater microalgae species, showing significant differences between the various species [15,16,20,21,24,32,41-68].

As shown in Table 1, oil content in microalgae can reach $75 \%$ by weight of dry biomass but associated with low productivities (e.g. for Botryococcus braunii). Most common algae (Chlorella, Crypthecodinium, Cylindrotheca, Dunaliella, Isochrysis, Nannochloris, Nannochloropsis, Neochloris, Nitzschia, Phaeodactylum, Porphyridium, Schizochytrium, Tetraselmis) have oil levels between 20 and 50\% but higher productivities can be reached.

Chlorella seems to be a good option for biodiesel production. Yet, as other species are so efficient and productive as this one, the selection of the most adequate species needs to take into account other factors, such as for example the ability of microalgae to develop using the nutrients available or under specific environmental conditions. All these parameters should be considered simultaneously in the selection of the most adequate species or strains for biodiesel production.

Also significant is the composition of fatty acids of the different microalgae species, as they can have a significant effect on the characteristics of biodiesel produced. These are composed of saturated and unsaturated fatty acids with 12-22 carbon atoms, some of them of $\omega 3$ and $\omega 6$ families. Thomas et al. [66] analyzed the fatty acid compositions of seven fresh water microalgae species showing that all of them synthesized C14:0, C16:0, C18:1, C18:2, and $\mathrm{C} 18: 3$ fatty acids. This author reported that the relative intensity of other individual fatty acids chains is species specific, e.g. C16:4 and C18:4 in Ankistrodesmus sp., C18:4 and C22:6 in Isochrysis sp., C16:2, C16:3 and C20:5 in Nannochloris sp., C16:2, C16:3, and C20:5 in Nitzschia sp.

Different nutritional and environmental factors, cultivation conditions and growth phases may affect the fatty acid composition. For example, nitrogen deficiency and salt stress induced the accumulation of C18:1 in all treated species and to some extent C20:5 in B. braunii [66]. Other authors also reported a differentiation between fatty acid composition of various algae species $[19,23,47,59,62,69]$

Although the microalgae oil yield is strain-dependent it is generally much greater than other vegetable oil crops, as shown in Table 2 that compares the biodiesel production efficiencies and land use of microalgae and other vegetable oil crops, including the amount of oil content in a dry weight basis and the oil yield per hectare, per year $[21,65,70-80]$.

Table 2 shows that although the oil contents are similar between seed plants and microalgae there are significant variations in the overall biomass productivity and resulting oil yield and biodiesel productivity with a clear advantage for microalgae. In terms of land use, microalgae followed by palm oil biodiesel are clearly advantageous because of their higher biomass productivity and oil yield.

\subsection{Microalgae biodiesel value chain stages}

Although in a simplistic view microalgae may seem to not significantly differ from other biodiesel feedstocks, they are microorganisms living essentially in liquid environments, and thus with particular cultivation, harvesting, and processing techniques that ought to be considered in order to efficiently produce biodiesel.

All existing processes for biodiesel production from microalgae include a production unit where cells are grown, followed by the separation of the cells from the growing media and subsequent lipids extraction. Then, biodiesel or other biofuels are produced in a form akin to existing processes and technologies used for other biofuels feedstocks. Recently other possibilities for biofuel production are being pursued instead of the transesterification reaction, such as the thermal cracking (or pyrolysis) involving the thermal decomposition or cleavage of the triglycerides and other organic compounds presented in the feedstock, in simpler molecules, namely alkans, alkenes, aromatics, carboxylic acids, among others [81-83].

Fig. 1 shows a schematic representation of the algal biodiesel value chain stages, starting with the selection of microalgae species depending on local specific conditions and the design and implementation of cultivation system for microalgae growth. Then, it follows the biomass harvesting, processing and oil extraction to supply the biodiesel production unit.

In the next subsections issues related to each algal biodiesel value chain stage are presented and discussed.

\subsubsection{Algae and site selection}

Currently a lot of research effort is being focused on the algal cultivation unit, as in most cases it represents the key step that

Table 2

Comparison of microalgae with other biodiesel feedstocks.

\begin{tabular}{|c|c|c|c|c|}
\hline Plant source & $\begin{array}{l}\text { Seed oil content } \\
\text { (\% oil by wt in biomass) }\end{array}$ & $\begin{array}{l}\text { Oil yield } \\
\text { (L oil/ha year) }\end{array}$ & $\begin{array}{l}\text { Land use } \\
\left(\mathrm{m}^{2} \text { year/kg biodiesel }\right)\end{array}$ & $\begin{array}{l}\text { Biodiesel productivity } \\
\text { (kg biodiesel/ha year) }\end{array}$ \\
\hline Corn/Maize (Zea mays L.) & 44 & 172 & 66 & 152 \\
\hline Hemp (Cannabis sativa L.) & 33 & 363 & 31 & 321 \\
\hline Soybean (Glycine $\max \mathrm{L}$.) & 18 & 636 & 18 & 562 \\
\hline Jatropha (Jatropha curcas L.) & 28 & 741 & 15 & 656 \\
\hline Camelina (Camelina sativa L.) & 42 & 915 & 12 & 809 \\
\hline Canola/Rapeseed (Brassica napus L.) & 41 & 974 & 12 & 862 \\
\hline Sunflower (Helianthus annuus L.) & 40 & 1070 & 11 & 946 \\
\hline Castor (Ricinus communis) & 48 & 1307 & 9 & 1156 \\
\hline Palm oil (Elaeis guineensis) & 36 & 5366 & 2 & 4747 \\
\hline Microalgae (low oil content) & 30 & 58,700 & 0.2 & 51,927 \\
\hline Microalgae (medium oil content) & 50 & 97,800 & 0.1 & 86,515 \\
\hline Microalgae (high oil content) & 70 & 136,900 & 0.1 & 121,104 \\
\hline
\end{tabular}




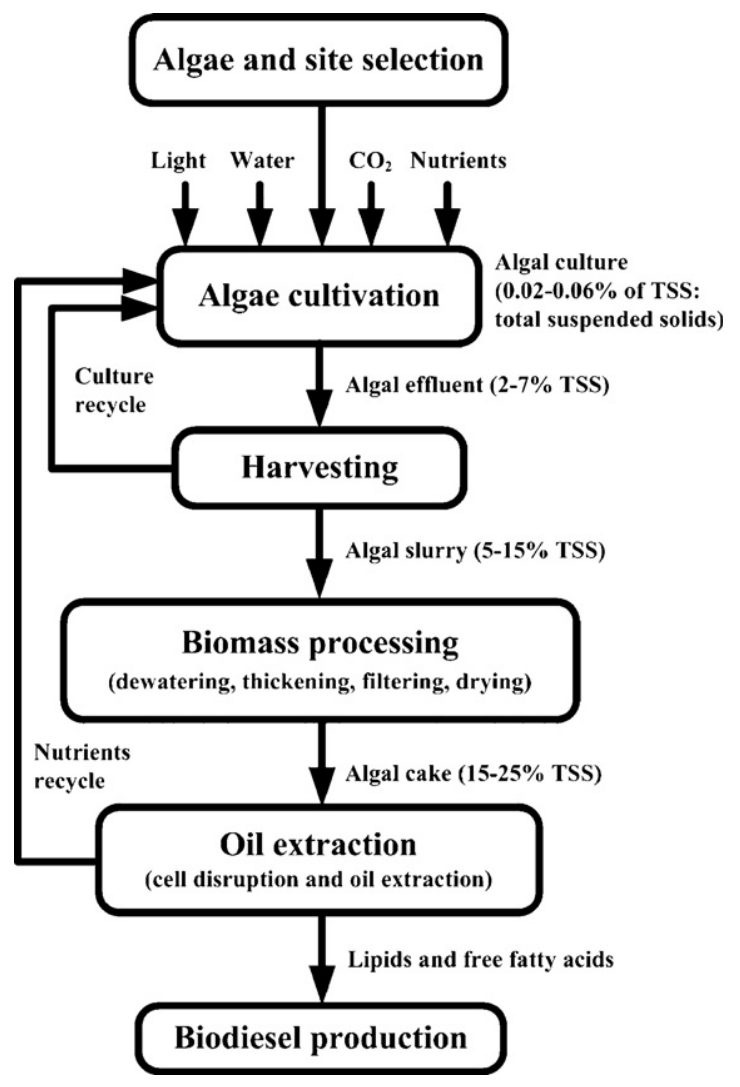

Fig. 1. Microalgae biodiesel value chain stages.

ultimately determines the economic viability of the process. According to Maxwell et al. [84] for the implementation of an algae cultivation unit a site selection and resource evaluation have to be performed considering several criteria: (i) the water supply/ demand, its salinity and chemistry; (ii) the land topography, geology, and ownership; (iii) the climatic conditions, temperature, insulation, evaporation, precipitation; (iv) the easy access to nutrients and carbon supply sources.

One needs also to decide if the algal cultivation unit will be operating in batch or continuous mode and if the production units will be open or close systems. This depends on the microalgae species selected, the expected environmental conditions, availability of nutrients and even the possibility to combine the microalgae growth with a pollution control strategy of other industry, for example for the removal of $\mathrm{CO}_{2}$ from flue gas emissions or the removal of nitrogen and phosphorus from a wastewater effluent.

Besides the equipment needed for microalgae growth, it is essential to pay close attention to the selection of the most adequate species and strains, their cultivation conditions and nutrients available for their growth. In most cases the production of biodiesel will rely on already available species and strains that have shown to be adequate due to either their lipid content or productivity. Literature information (as the one summarized in Table 1) and obtained from companies supplying production units can also be used. However, in some cases this approach may not yield an adequate solution and thus a search for more convenient microalgae species has to be done. Typically sources of microalgae include existing collections of microalgae, commercially available either from Universities or other national and international foundations (such as the ones previously mentioned) or from companies specifically devoted to algae growth [37], or water and soil samples obtained from diverse environments.
As microalgae will have to live and thrive in a wide range of environmental conditions, especially of nutrients scarcity and other adverse conditions, algae samples obtained in harsh environments such as thermal springs or industrial wastewaters can be used. This way it is ensured that if any viable option is found it will be robust and possibly better adapted to specific conditions.

The sampling and selection process is well established, although it requires specialized equipment and may be time consuming [16]. A multicriteria strategy has to be considered in this process, considering factors such as follows:

- Growing rate, normally measured by total amount of biomass accumulated per unit time and unit volume;

- Lipid content, not total amount but the distribution of free fatty acids and triglycerides, a factor that may be relevant in biodiesel production;

- Resistance to environmental conditions changes, in particular of temperature, nutrients input, light, competition from other microalgae species and/or bacterial;

- Nutrients availability, in particular of carbon dioxide sources when the goal of carbon sequestration is also deemed relevant;

- Ease of biomass separation and processing;

- Possibility of obtaining other valuable chemicals.

The listed criteria consider not only the microalgae themselves but also their cultivation units. Thus, all experiments should mimic as much as possible the real conditions where the microorganisms will be used and include the biomass processing stages before the production of biodiesel itself.

Even when the species listed in literature or obtained from the environment are not adequate, the utilization of genetic engineering may be a solution [85]. This way it is possible to adjust the characteristics of microalgae to the process and desired product(s) and to improve the productivity and lipid yield and composition. However, the fears of biological contamination, restrictive legislation and viable natural options still hinder the broader utilization of genetically engineered organisms.

Although probably lengthy in time and cost intensive, obtaining an organism that better suits the specific operating conditions has some advantages. Firstly, it frees the company that produces biodiesel from microalgae to be dependent from suppliers, and generates in house expertise that can be advantageous in future. Secondly, the identification of new species or the development of new strains represents a business opportunity and source of income from the possible royalties resulting from its intellectual property.

Therefore, it is crucial to understand how to select the right algae species, create an optimal photo-biological formula for each species, and build a cost-effective cultivation unit that can precisely deliver the formula to each individual algae cell, no matter the size of the facility, or its geographical location.

\subsubsection{Algae cultivation}

Microalgae are adapted to scavenge their environments for resources, to storage them, or increase their efficiency in resource utilization. In general for biomass growth (consisting of $40-50 \%$ carbon) microalgae depend on a sufficient supply of a carbon source and light to carry out photosynthesis $[57,86]$. Yet they can adjust or change their internal structure (e.g. biochemical and physiological acclimation), whilst externally they can excrete a variety of compounds to amongst others, render nutrients available or limit the growth of competitors [16].

Microalgae may assume many types of metabolisms (e.g. autotrophic, heterotrophic, mixotrophic, photoheterotrophic) and are capable of a metabolic shift as a response to changes in 
the environmental conditions. For example some organisms can grow [87]:

- Photoautotrophically, i.e. using light as a sole energy source that is converted to chemical energy through photosynthetic reactions.

- Heterotrophically, i.e. utilizing only organic compounds as carbon and energy source.

- Mixotrophically, i.e. performing photosynthesis as the main energy source, though both organic compounds and $\mathrm{CO}_{2}$ are essential. Amphitrophy, subtype of mixotrophy, means that organisms are able to live either autotrophically or heterotrophically, depending on the concentration of organic compounds and light intensity available.

- Photoheterotrophycally, also known as photoorganitrophy, photoassimilation, photometabolism, describes the metabolism in which light is required to use organic compounds as carbon source. The photoheterotrophic and mixotrophic metabolisms are not well distinguished, in particular they can be defined according to a difference of the energy source required to perform growth and specific metabolite production.

The metabolism involved can also be distinguished according to $\mathrm{pH}$ changes that depend on the microalgae growth stoichiometry. Chlorella vulgaris, Haematococcus pluvialis, Arthrospira (Spirulina) platensis are examples of strains found to grow under photoautotrophic, heterotrophic, as well as under mixotrophic conditions. Other strains such as Selenastrum capricornutum and Scenedesmus acutus can grow either photoautotrophically, heterotrophically, or photoheterotrophically [87].

Not only organic carbon or substract (a carbon source such as sugars, proteins and fats), vitamins, salts and other nutrients (nitrogen and phosphorous) are vital for algal growth, but also equilibrium between operational parameters (oxygen, carbon dioxide, $\mathrm{pH}$, temperature, light intensity, and product and byproduct removal) [88].

When considering algal use for biodiesel production, it is yet important to quantitatively define the influence of these operational parameters and their interrelation to be able to manipulate them. This way one may succeed in obtaining a certain control over the composition of microalgae populations, even on a large scale. As stated by De Pauw et al. [89], experience has repeatedly shown that properly managed algal cultures are quite resistant and that infections are often an indication of poor culture conditions.

Under suitable climatic conditions and sufficient nutrients, microalgae can grow profusely. Commonly they double their biomass within $24 \mathrm{~h}$ or within $3.5 \mathrm{~h}$ during the exponential growth phase [21].

Fig. 2 represents the algae growth curve in a batch culture (solid line) and nutrients concentration (dashed line), where five

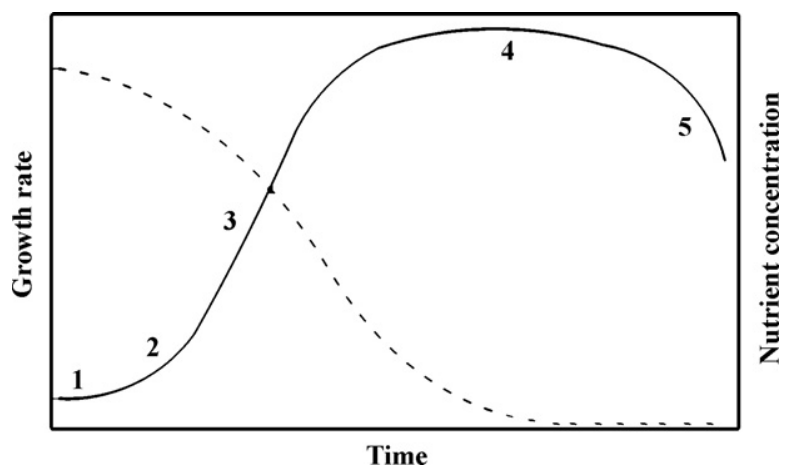

Fig. 2. Schematic representation of algae growth rate in batch culture (solid line) and nutrients concentration (dashed line). reasonably well defined growth phases can be recognized: (1) lag phase; (2) exponential growth phase, representing the maximum growth rate under the specific conditions; (3) linear growth phase; (4) stationary growth phase; (5) decline or death phase.

The opposite pattern of the dashed curve (in Fig. 2) indicates the nutrients depletion during the stationary phase and onwards.

Generally algal cultures in the exponential growth phase contain more protein, while cultures in the stationary phase have more carbohydrates and glycogen. For example, according to De Pauw et al. [89] oysters fed by algae of the former type usually grow less.

A major handicap in the large-scale cultivation of algae is our inability to grow selected species in substantial volumes of hundreds of cubic meters. Exceptions are for example Chlorella and Spirulina used in aquaculture [89]. A premature collapse may occur when up-scaling cultures of algae strains to larger volumes, in an artificially protected environment of semi-sterility, or other species better adapted to outdoor conditions can take-over. This means that they were developed under unbalanced growth conditions and should be better defined, in the exponential growth phase, for high-density cultures.

There are several factors influencing algal growth: abiotic factors such as light (quality, quantity), temperature, nutrient concentration, $\mathrm{O}_{2}, \mathrm{CO}_{2}, \mathrm{pH}$, salinity, and toxic chemicals; biotic factors such as pathogens (bacteria, fungi, viruses) and competition by other algae; operational factors such as shear produced by mixing, dilution rate, depth, harvest frequency, and addition of bicarbonate.

Temperature is the most important limiting factor, after light, for culturing algae in both closed and open outdoor systems. The temperature effects for many microalgae species in the laboratory are well documented, but the magnitude of temperature effects in the annual biomass production outdoors is not yet sufficiently acknowledged. Many microalgae can easily tolerate temperatures up to $15^{\circ} \mathrm{C}$ lower than their optimal, but exceeding the optimum temperature by only $2-4{ }^{\circ} \mathrm{C}$ may result in the total culture loss. Also, overheating problems may occur in closed culture systems during some hot days, where the temperature inside the reactor may reach $55^{\circ} \mathrm{C}$. In this case evaporative water cooling systems may be economically used to decrease the temperature to around 20-26 ${ }^{\circ} \mathrm{C}$ [57].

Salinity, in both open and closed systems, can affect the growth and cell composition of microalgae. Every alga has a different optimum salinity range that can increase during hot weather conditions due to high evaporation. Salinity changes normally affect phytoplankton in three ways [57]: (1) osmotic stress (2) ion (salt) stress; and (3) changes of the cellular ionic ratios due to the membrane selective ion permeability. The easiest way for salinity control is by adding fresh water or salt as required.

Mixing is another important growth parameter since it homogenizes the cells distribution, heat, metabolites, and facilitates transfer of gases. Also, a certain degree of turbulence, especially in large-scale production, is desirable in order to promote the fast circulation of microalgae cells from the dark to the light zone of the reactor [90]. In other hand high liquid velocities and degrees of turbulence (due to mechanical mixing or air bubbles mixing) can damage microalgae due to shear stress [45]. The optimum level of turbulence (above which cell death occurs) is strain dependent and should be investigated in order to avoid decline in productivity [90].

Common biological contaminants observed include unwanted algae, mould, yeast, fungi, and bacteria. Attempts made to cultivate some microalgae species in raceway ponds failed, since cultures collapse due to predation by protozoa and contamination by other algal species.

As referred by Moheimani [57] a way to decrease contaminants and improve yield is after removing the unwanted organism to 
subject the culture to a temporarily extreme change of the environmental factors such as temperature, $\mathrm{pH}$, or light. The closed environment, the higher degree of control over culture parameters, and the higher cell concentration attainable in closed cultivation reactors effectively protect the culture from contamination and make cultivation of some important microalgae feasible.

The effects of different cultivation factors on algal growth have been examined by various authors:

- Moheimani [57] analyzed the effects of a reduction in the medium $\mathrm{pH}$, resulting from $\mathrm{CO}_{2}$, which may inhibit the algal growth. This author determined that for Pleurochrysis carterae the $\mathrm{pH}$ range for maximum productivities in a plate photobioreactor is $\mathrm{pH} 7.7-8.0$ and in an outdoor raceway pond is $\mathrm{pH}$ 9.1-9.6. This author also determined a best operational depth for the outdoor raceway pond between 16 and $21 \mathrm{~cm}$.

- Richmond [16] reported that supplying $\mathrm{CO}_{2}$ in shallow suspensions at near neutral $\mathrm{pH}$ is difficult to control, since the bubbles residence time is insufficient to complete the absorption, resulting in great $\mathrm{CO}_{2}$ losses to the atmosphere.

- Weissman and Goebel [91] explain that the absorption of $\mathrm{CO}_{2}$ into alkaline waters may be accelerated by one of two major uncatalyzed reaction paths, the hydration of $\mathrm{CO}_{2}$ and subsequent acid-base reaction to form bicarbonate ion and the direct reaction of $\mathrm{CO}_{2}$ with the hydroxyl ion to form bicarbonate. This author refers that the rate of the former reaction is faster at $\mathrm{pH}$ values below 8, while the second dominates above $\mathrm{pH} 10$. Between 8 and 10 both can be important.

- Chiu et al. [42] results show an increase in the biomass production and lipid accumulation with a $\mathrm{CO}_{2}$ concentration increase in the aeration of Nannochloropsis oculata cultures.

- Similar results were obtained by De Morais and Costa [43] for Scenedesmus obliquus and Chlorella kessleri cultures, isolated from a treatment pond of a coal fired thermoelectric power plant in Brazil, concluding that these microalgae have the potential for bio-fixation of $\mathrm{CO}_{2}$ in thermoelectric power plants.

- Other important factors are aeration and light intensity. Kaewpintong [86] reported a better growth for an airlift bioreactor than for an unaerated column. This is explained because aeration lead to a better mixing of the microalgal culture, which prevents sedimentation, maintains homogeneous conditions, and helps for a better contact between cells and nutrients. This author also reports an increase in cell density and specific growth rate with an increase in the light intensity up to a certain limit, above which the growth was inhibited.

- Thomas et al. [66] investigated photosynthetic algae species that grow autotrophically on a mineral medium containing carbon dioxide (and bicarbonate) as a carbon source and nitrate as a nitrogen source. The main purpose of this study is to determine the effect of nitrogen as well as the salt stress on the proximate chemical compositions of the algae. The general conclusion is that the species tested differ in their basic cellular composition when they are exposed to environmental stress. On growth under non-stressed conditions, Botryococcus contained the highest concentration of lipids the greatest proportion of which is hydrocarbon in nature. All other algae contained lower levels of lipids with an average of $23 \%$ per organic weight for the green algae, $12 \%$ for Nitzschia sp. and 7\% for Isochrysis.

- Liu et al. [92] showed that high iron concentration could also induce considerable lipid accumulation in marine strain $C$. vulgaris. This suggests that some metabolic pathways related to the lipid accumulation in $C$. vulgaris are probably modified by high level of iron concentration in the initial medium.

- Illman et al. [50] found that the reduction in nitrogen in the medium increases the lipid content in all five investigated Chlorella strains, among which C. emersonii, C. minutissima and C. vulgaris gained an increase in lipid contend of 63\%, 56\% and 40\% biomass by dry weight respectively.

- Thomas et al. [66] also studied the effect of nitrogen stress on algae lipid fraction, concluding that cultivation under nitrogen deficient conditions did indeed increase the neutral lipid contents, but it cannot be summarized as a single trend. This is observed for Botryococcus, Isochrysis and Dunaliella species grown under nitrogen stress. In Botryococcus the neutral lipids comprised a major proportion of the total lipids. However, the greatest neutral lipid production occurred in the resting stage and the greatest amount is formed in the conversion of the algae from the green to the brown growth phase. In contrast to the $10 \%$ increase in the Botryococcus lipids, there was a drop in the lipid fraction in Dunaliella bardawil and Dunaliella salina to about 10\% of the organic weight. These halotolerant green algae shifted towards carbohydrate storage under nitrogen stress. On the other hand, Isochrysis accumulated higher fractions of lipids and carbohydrates under nitrogen deficiency, with lipids comprising about one-fourth of the algal organic cell weight following 10 days of nitrogen starvation. In general, the effects of nitrate deficiency were that the protein content and the chlorophyll level decreased while carbohydrate and lipids exhibited a species-specific change. The neutral lipid content is expressed in the algae that shift to lipid storage when under environmental stress. These neutral lipids are not predominantly straight chain saturated hydrocarbons but multibranched and/or polyunsaturated components.

- Macedo and Alegre [93] demonstrated that the Spirulina lipids content increase approximately 3 times with the decrease of nitrogen content and temperature decrease, being the nitrogen concentration decrease more effective.

\subsubsection{Harvesting and biomass concentration}

Algal harvesting consists of biomass recovery from the culture medium that may contribute to $20-30 \%$ of the total biomass production cost [94]. In order to remove large quantities of water and process large algal biomass volumes, a suitable harvesting method may involve one or more steps and be achieved in several physical, chemical, or biological ways, in order to perform the desired solid-liquid separation. Experience has demonstrated that albeit a universal harvesting method does not exist, this is still an active area for research, being possible to develop an appropriate and economical harvesting system for any algal species.

Most common harvesting methods include sedimentation, centrifugation, filtration, ultra-filtration, sometimes with an additional flocculation step or with a combination of flocculation-flotation. Flocculation is used to aggregate the microalgal cells to increase the effective particle size and hence ease sedimentation, centrifugal recovery, and filtration [94]. Weissman and Goebel [91] studied four primary harvesting methods for the purpose of biofuels production: microstraining, belt filtering, flotation with float collection, and sedimentation. These methods discriminate on a size and density basis in performing the biomass separation. Microstrainers are an attractive harvesting method because of their mechanical simplicity and availability in large unit sizes. The recent availability of very fine mesh polyester screens has revived interest in their use for microalgae harvesting. Subsequent studies concluded that it would be necessary to flocculate the cells prior to microstraining.

Filter presses operating under pressure or vacuum can be used to recover large quantities of biomass, but for some applications filtration can be relatively slow which may be unsatisfactory. Also filtration is better suited for large microalgae such as Coelastrum proboscideum and $S$. platensis but cannot recover organisms with smaller dimensions such Scenedesmus, Dunaliella, or Chlorella [94]. Alternatively, membrane microfiltration and ultra-filtration are 
other possible alternatives to conventional filtration for recovering algal biomass, which are more suitable for fragile cells and smallscale production processes. Furthermore these filtration processes are more expensive especially because of the need for membrane replacement and pumping.

Richmond [16] suggested one main criterion for selecting a proper harvesting procedure, which is the desired product quality. In one hand for low value products, gravity sedimentation may be used, possibly enhanced by flocculation. Sedimentation tanks or settling ponds are also possible, e.g. to recover biomass from sewage-based processes. In other hand for high-value products, to recover high quality algae such as for food or aquaculture applications, it is often recommended to use continuously operating centrifuges that can process large volumes of biomass. Albeit at considerable cost, centrifuges are suitable to rapidly concentrate any type of microorganisms, which remain fully contained during recovery. Additionally, these devices can be easily cleaned or sterilized to effectively avoid bacterial contamination or fouling of raw product.

Another basic criterion for selecting the harvesting procedure is its potential to adjust the density or the acceptable level of moisture in the resulting concentrate right to the optimum subsequent process [16,94]. Gravity sedimented sludge is generally more diluted than centrifugally recovered biomass, which substantially influence the economics of product recovery further downstream. Since costs of thermal drying are much higher than those of mechanical dewatering, in order to reduce the overall production cost, a concentrate with higher solids content is required after harvest to easy biomass dehydration (e.g. in a drumdrying). In this case a combination of methods can also be used, e.g. a pre-concentration with a mechanical dewatering step such as microstrainer, filtration, or centrifugation and then, a postconcentration by means of a screw centrifuge or a thermal drying.

After separation from the culture medium algal biomass (5-15\% dry weight) must be quickly processed lest it should get spoiled in only a few hours in a hot climate.

\subsubsection{Processing and components extraction}

Processing represents a major economic limitation to the production of low cost commodities (fuels, feeds and foods) and also to higher value products ( $\beta$-carotene, polysaccharides). It is difficult to discuss processing, since it is highly specific and strongly depends on the desired products.

It is common to apply dehydration of biomass that also increases its shelf-life and of the final product. Several methods have been employed to dry microalgae such as Chlorella, Scenedesmus and Spirulina, where the most common include spray-drying, drumdrying, freeze-drying and sun-drying [16]. Because of the high water content of algal biomass sun-drying is not a very effective method for algal powder production and spray-drying is not economically feasible for low value products, such as biofuel or protein.

After drying it follows the cell disruption of the microalgae cells for release of the metabolites of interest. Several methods can be used depending on the microalgae wall and on the product nature to be obtained either based on mechanical action (e.g. cell homogenizers, bead mills, ultrasounds, autoclave, and spray drying) or non-mechanical action (e.g. freezing, organic solvents and osmotic shock and acid, base and enzyme reactions).

Taking the example of the astaxanthin recovery, although different methods have been studied the best results were obtained from autoclaved and mechanically disrupted biomass, with yield 3 times higher than with other methods [16]. Lyophilization breaks up the cells and turns the algal material into a loose and fine powder, making other treatment unnecessary.

For biodiesel production, lipids and fatty acids have to be extracted from the microalgal biomass. For lipids a solvent extraction is normally done directly from the lyophilized biomass, being a quick and efficient extraction method that slightly reduces the degradation. Several solvents can be used such as hexane, ethanol (96\%), or a hexane-ethanol (96\%) mixture, being possible to obtain up to $98 \%$ quantitative extraction of purified fatty acids [16]. Although ethanol is a very good solvent it can also extract some cellular contaminants such as sugars, amino acids, salts, hydrophobic proteins and pigments, which is not desirable if the purpose of the extraction is just the lipids.

Extraction methods such as ultrasound and microwaveassisted were also studied for oil extraction from vegetable sources. Cravotto et al. [95] compared oil extraction times and yields using these methods with those resulting from conventional procedures. For that purpose these authors research team developed ultrasound devices working at frequencies of 19, 25, 40 and $300 \mathrm{kHz}$ and multimode microwave oven operating with both open and closed vessels, as well as combined extraction with simultaneous double sonication at 19 and $25 \mathrm{kHz}$ and simultaneous ultrasound/multimode microwave irradiation achieved. These results indicate that compared with conventional methods these new methods can greatly improve oil extraction with higher efficiency. Extraction times were reduced and yields increased by $50-500 \%$ with low or moderate costs and minimal added toxicity. In the case of marine microalgae Crypthecodinium cohnii, ultrasound worked best as the disruption of the tough algal cell wall considerably improved the extraction yield from $4.8 \%$ (in soxhlet) to $25.9 \%$.

\subsubsection{Biodiesel production}

Biodiesel is a mixture of fatty acid alkyl esters obtained by transesterification (ester exchange reaction) of vegetable oils or animal fats. These lipid feedstocks are composed by $90-98 \%$ (weight) of triglycerides and small amounts of mono and diglycerides, free fatty acids (1-5\%), and residual amounts of phospholipids, phosphatides, carotenes, tocopherols, sulphur compounds, and traces of water [9].

Transesterification is a multiple step reaction, including three reversible steps in series, where triglycerides are converted to diglycerides, then diglycerides are converted to monoglycerides, and monoglycerides are then converted to esters (biodiesel) and glycerol (by-product). The overall transesterification reaction is described in Fig. 3 where the radicals R1, R2, R3 represent long chain hydrocarbons, known as fatty acids.

For the transesterification reaction oil or fat and a short chain alcohol (usually methanol) are used as reagents in the presence of a catalyst (usually $\mathrm{NaOH}$ ). Although the alcohol:oil theoretical molar ratio is $3: 1$, the molar ratio of $6: 1$ is generally used to complete the reaction accurately. The relationship between the feedstock mass input and biodiesel mass output is about $1: 1$, which means that theoretically, $1 \mathrm{~kg}$ of oil results in about $1 \mathrm{~kg}$ of biodiesel.

A homogeneous or heterogeneous, acid or basic catalyst can be used to enhance the transesterification reaction rate, although for some processes using supercritical fluids (methanol or ethanol) it may not be necessary to use a catalyst [96]. Most common

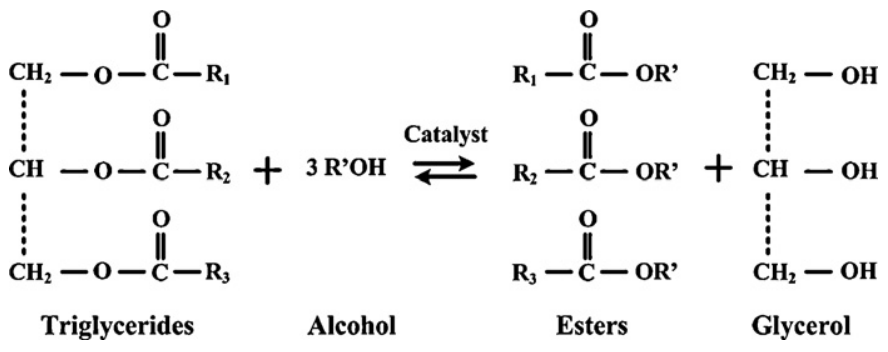

Fig. 3. Transesterification of triglycerides (overall reaction). 
industrial processes use homogeneous alkali catalysts (e.g. $\mathrm{NaOH}$ or $\mathrm{KOH}$ ) in a stirred reactor operating in batch mode.

Recently some improvements were proposed for this process, in particular to be able to operate in continuous mode with reduced reaction time, such as reactors with improved mixing, microwave assisted reaction $[95,97]$, cavitation reactors $[98,99]$ and ultrasonic reactors $[100,101]$.

\subsection{Microalgae culture systems}

\subsubsection{Open versus closed-culture systems}

Microalgae cultivation can be done in open-culture systems such as lakes or ponds and in highly controlled closed-culture systems called photo-bioreactors (PBRs). A bioreactor is defined as a system in which a biological conversion is achieved. Thus, a photo-bioreactor is a reactor in which phototrophs (microbial, algal or plant cells) are grown or used to carry out a photobiological reaction. Although this definition may apply to both closed and open-culture systems, for the purpose of this article we limit the definition to the former ones.

Open-culture systems are normally less expensive to build and operate, more durable than large closed reactors and with a large production capacity when compared with closed systems. However According to Richmond [16] ponds use more energy to homogenize nutrients and the water level cannot be kept much lower than $15 \mathrm{~cm}$ ( or $150 \mathrm{~L} / \mathrm{m}^{2}$ ) for the microalgae to receive enough solar energy to grow. Generally ponds are more susceptive to weather conditions, not allowing control of water temperature, evaporation and lighting. Also, they may produce large quantities of microalgae, but occupy more extensive land area and are more susceptible to contaminations from other microalgae or bacteria. Moreover, since atmosphere only contains $0.03-0.06 \% \mathrm{CO}_{2}$ it is expected that mass transfer limitation could slow down the cell growth of microalgae.

PBRs are flexible systems that can be optimized according to the biological and physiological characteristics of the algal species being cultivated, allowing one to cultivate algal species that cannot be grown in open ponds. On a PBR, direct exchange of gases and contaminants (e.g. microorganisms, dust) between the cultivated cells and atmosphere are limited or not allowed by the reactor's walls. Also, a great proportion of light does not impinge directly on the culture surface but has to cross the transparent reactor walls.

Depending on their shape or design, PBRs are considered to have several advantages over open ponds: offer better control over culture conditions and growth parameters $(\mathrm{pH}$, temperature, mixing, $\mathrm{CO}_{2}$ and $\mathrm{O}_{2}$ ), prevent evaporation, reduce $\mathrm{CO}_{2}$ losses, allow to attain higher microalgae densities or cell concentrations, higher volumetric productivities, offer a more safe and protected environment, preventing contamination or minimizing invasion by competing microorganisms.

Despite their advantages it is not expected that PBR have a significant impact in the near future on any product or process that can be attained in large outdoor raceway ponds. PBRs suffer from several drawbacks that need to be considered and solved. Their main limitations include: overheating, bio-fouling, oxygen accumulation, difficulty in scaling up, the high cost of building, operating and of algal biomass cultivation, and cell damage by shear stress and deterioration of material used for the photo-stage.

The cost of biomass production in PBRs may be one order of magnitude higher than in ponds. While in some cases, for some microalgae species and applications it may be low enough to be attractive for aquaculture use, in other cases, the higher cell concentration and the higher productivity achieved in PBR may not compensate for its higher capital and operating costs.

Table 3 makes a comparison between PBR and ponds for several culture conditions and growth parameters [102-106].
Comparison of performances achieved by PBRs and open ponds may not be easy, as the evaluation depends on several factors, among which the algal species cultivated and the method adopted to compute productivity. There are three parameters commonly used to evaluate productivity in algae production units [16]:

- Volumetric productivity (VP): productivity per unit reactor volume (expressed as g/L d).

- Areal productivity (AP): productivity per unit of ground area occupied by the reactor (expressed as $\mathrm{g} / \mathrm{m}^{2} \mathrm{~d}$ ).

- Illuminated surface productivity (ISP): productivity per unit of reactor illuminated surface area (expressed as $\mathrm{g} / \mathrm{m}^{2} \mathrm{~d}$ ).

As stated by Richmond [16] despite closed systems offer no advantage in terms of areal productivity, they largely surpass ponds in terms of volumetric productivity ( 8 times higher) and cell concentration (about 16 times higher).

In conclusion, PBR and open ponds should not be viewed as competing technologies, but the real competing technology will be genetic engineering [16,85].

\subsubsection{Batch versus continuous operation}

PBR can be operated in batch or continuous mode. There are several advantages of using continuous bioreactors as opposed to the batch mode [88]:

- Continuous bioreactors provide a higher degree of control than do batch;

- Growth rates can be regulated and maintained for extended time periods and biomass concentration can be controlled by varying the dilution rate;

- Because of the steady-state of continuous bioreactors, results are more reliable and easily reproducible and the desired product quality may be more easily obtained;

Table 3

A comparison of open and closed large-scale culture systems for microalgae.

\begin{tabular}{|c|c|c|}
\hline $\begin{array}{l}\text { Culture systems } \\
\text { for microalgae }\end{array}$ & Closed systems (PBRs) & $\begin{array}{l}\text { Open systems } \\
\text { (Ponds) }\end{array}$ \\
\hline Contamination control & Easy & Difficult \\
\hline Contamination risk & Reduced & High \\
\hline Sterility & Achievable & None \\
\hline Process control & Easy & Difficult \\
\hline Species control & Easy & Difficult \\
\hline Mixing & Uniform & Very poor \\
\hline Operation regime & Batch or semi-continuous & $\begin{array}{l}\text { Batch or } \\
\text { semi-continuous }\end{array}$ \\
\hline Space required & A matter of productivity & PBRs $\sim$ Ponds \\
\hline Area/volume ratio & $\operatorname{High}\left(20-200 \mathrm{~m}^{-1}\right)$ & $\operatorname{Low}\left(5-10 \mathrm{~m}^{-1}\right)$ \\
\hline $\begin{array}{l}\text { Population (algal cell) } \\
\text { density }\end{array}$ & High & Low \\
\hline Investment & High & Low \\
\hline Operation costs & High & Low \\
\hline $\begin{array}{l}\text { Capital/operating } \\
\text { costs ponds }\end{array}$ & Ponds $3-10$ times lower cost & PBRs $>$ Ponds \\
\hline $\begin{array}{l}\text { Light utilization } \\
\text { efficiency }\end{array}$ & High & Poor \\
\hline Temperature control & More uniform temperature & Difficult \\
\hline Productivity & 3-5 times more productive & Low \\
\hline Water losses & Depends upon cooling design & PBRs $\sim$ Ponds \\
\hline $\begin{array}{l}\text { Hydrodynamic stress } \\
\text { on algae }\end{array}$ & Low-high & Very low \\
\hline $\begin{array}{l}\text { Evaporation of growth } \\
\text { medium }\end{array}$ & Low & High \\
\hline Gas transfer control & High & Low \\
\hline $\mathrm{CO}_{2}$ losses & Depends on $\mathrm{pH}$, alkalinity, etc. & PBRs $\sim$ Ponds \\
\hline $\mathrm{O}_{2}$ inhibition & Greater problem in PBRs & PBRs $>$ Ponds \\
\hline Biomass concentration & $3-5$ times in PBRs & PBRs $>$ Ponds \\
\hline Scale-up & Difficult & Difficult \\
\hline
\end{tabular}


- Continuous reactions offer increased opportunities for system investigation and analysis.

There are yet inherent disadvantages that may make this process unsuitable for some types of bio-reaction. For example, one challenge lies in controlling the production of some non-growthrelated products. For this reason, the continuous process often requires feed-batch culturing, and a continuous nutrient supply. Wall growth and cell aggregation can also cause wash-out or prevent optimum steady-state growth.

Another problem is that the original product strain can be lost over time, if it is overtaken by a faster-growing one. The mixture viscosity and its heterogeneous nature can make it difficult to maintain filamentous organisms. Long growth periods not only increase the contamination risk, but also dictate that the bioreactor must be extremely reliable and consistent, incurring a potentially larger initial expenditure in higher-quality equipment.

\subsubsection{Designs and construction materials of culture systems}

Depending on the local conditions and available materials it is possible to design different culture systems with variations in size, shape, construction materials, inclination and agitation type, which influence their performance, cost and durability (resistance to weathering).

Among the various sizes and shapes of ponds operated at a relatively large scale the three major designs include [16,26]: (1) raceway ponds constructed as an endless loop, in which the culture is circulated by paddle wheels; (2) circular ponds with agitation provided by a rotating arm; (3) inclined systems where mixing is achieved through pumping and gravity flow.

Raceway ponds and also natural ponds may be the most commonly used for commercial production of microalgae. Normally open ponds are relatively economical, easy to clean up after cultivation and good for mass cultivation of algae. However they allow little control of culture conditions, their productivity is poor, occupy large land area, cultures are easily contaminated, are limited to few strains of algae, and have difficulty in growing algal cultures for long periods [67].

PBRs can be classified on the basis of both design and mode of operation. Many different designs have been developed (serpentine, manifold, helical, and flat), where the main categories include [16]: (1) flat or tubular; (2) horizontal, inclined, vertical or spiral; and (3) manifold or serpentine. From these, elevated reactors can be oriented and tilted at different angles and can use diffuse and reflected light, which plays an important role in productivity.

Generally tubular reactors are suitable for outdoor cultures, are relatively cheap, have a large illumination surface area and have fairly good biomass productivities. Disadvantages include fouling, some degree of wall growth, dissolved oxygen and $\mathrm{CO}_{2}$ along the tubes, and the $\mathrm{pH}$ gradients [67].

Vertical bubble columns and airlift cylinders can attain substantially increased radial movement of fluid that is necessary for improved light-dark cycling. These reactor designs have a low surface/volume, but substantially greater gas hold-ups than horizontal reactors and a much more chaotic gas-liquid flow $[16,67]$. Other prospects include high mass transfer, good mixing with low shear stress, low energy consumption, high potential for scalability, easy to sterilize, readily tempered, good for immobilization of algae. Consequently, cultures suffer less from photoinhibition and photo-oxidation, and experience a more adequate light-dark cycle. Limitations include their cost, small illumination surface area, their construction requires sophisticated materials, shear stress to algal cultures, and the fact that, since diameter and height cannot be much increased, a large number of units are needed to build a commercial plant.

Vertical plate photo-bioreactors mixed by air bubbling seem even better than bubble columns in terms of productivity and ease of operation. Flat-plates allow large illumination surface area, are suitable for outdoor cultures, are good for algae immobilization, relatively cheap, easy to clean up and readily tempered [67]. It has been shown that vertical flat plates of 1000-2000 L in volume can be successfully operated for long periods, hence having potential for scale up [16]. Packed flat panels mixed by air bubbling can potentially achieve very high overall ground-areal productivities through lamination of solar light. Limitations include difficulty in controlling culture temperature, some degree of wall growth, scale-up require many compartments and support materials, and possibility of hydrodynamic stress to some algal strains [67].

PBR can be built with various light paths and can be mixed by different types of pumps or by air bubbling, key issues to reach very high productivities and efficiencies of solar energy utilization. The type of material used for the photo-stage is of fundamental importance for a suitable PBR construction. Materials such as plastic or glass sheets, collapsible or rigid tubes, must lack toxicity, have high transparency, high mechanical strength, high durability, chemical stability and low cost [16]. The ease of cleaning and loss of the plastics transparency exposed outdoors are operational issues to consider.

According to Richmond [16] the construction materials to build the side walls and bottom of a pond can vary from simple sand or clay, to brick or cement, and to expensive plastics like PVC, glass fiber or polyurethane. For the lining most commercial plants use long-life plastic membranes (e.g. 1-2 mm thick, UV-resistant, PVC or polyethylene sheets). Sometimes unlined ponds are used to reduce costs, but they suffer from silt suspension, percolation, heavy contamination, and their use is limited to a few algal species and to particular soil and environmental conditions.

\section{Other applications and products from microalgae}

\subsection{Environmental applications}

Production of biodiesel and other bio-products from microalgae can be more environmentally sustainable, cost-effective and profitable, if combined with processes such as wastewater and flue gas treatments. In fact various studies demonstrated the use of microalgae for production of valuable products combined with environmental applications [107-111].

\subsubsection{Flue gas $\mathrm{CO}_{2}$ emissions as microalgae nutrient}

Two main $\mathrm{CO}_{2}$ mitigation strategies are normally used [29]: the chemical reaction-based approaches and the biological mitigation. In one hand, the chemical reaction-based $\mathrm{CO}_{2}$ mitigation approaches are energy-consuming, use costly processes, and have disposal problems because both the captured carbon dioxide and the wasted absorbents need to be disposed of. In other hand, the biological $\mathrm{CO}_{2}$ mitigation has attracted much attention in the last years since it leads to the production of biomass energy in the process of $\mathrm{CO}_{2}$ fixation through photosynthesis [40].

Flue gases from power plants are responsible for more than $7 \%$ of the total world $\mathrm{CO}_{2}$ emissions from energy use [112]. Also, industrial exhaust gases contains up to $15 \% \mathrm{CO}_{2}[113,114]$, providing a $\mathrm{CO}_{2}$-rich source for microalgae cultivation and a potentially more efficient route for $\mathrm{CO}_{2}$ bio-fixation. Therefore, to use a flue gas emission from an industrial process unit (e.g. from fuel-fired power plants) as a source of $\mathrm{CO}_{2}$ for the microalgae growth is envisioned to have a great potential to diminish $\mathrm{CO}_{2}$ and to provide a very promising alternative to current GHG emissions mitigation strategies.

The laboratory studies carried out by Zeiler et al. [115] using a green alga Monoruphidium minutum, demonstrated that this alga can efficiently utilize simulated flue gas containing high levels of carbon dioxide, as well as sulfur and nitrogen oxides, as a feedstock to 
produce substantial biomass. In this study several important parameters for productivity have been identified including nutrient levels and sparging regime. The green algae Chlorophyta showed the ability to fix $\mathrm{CO}_{2}$ while capturing solar energy with an efficiency of 10-50 times greater than that of terrestrial plants [29].

For that reason, it is beneficial if microalgae are tolerant to high carbon dioxide levels in order to be used for its fixation from flue gases. Chlorococcum littorale a marine alga, showed exceptional tolerance to high $\mathrm{CO}_{2}$ concentration of up to $40 \%$ [116]. Chlorella Strains from hot springs, also showed to be tolerant to high temperatures up to $42{ }^{\circ} \mathrm{C}$, for $\mathrm{CO}_{2}$ fixation from industrial flue gases containing up to $40 \% \mathrm{CO}_{2}$ [117]. Microalgae $S$. obliquus and $C$. kessleri, separated from the waste treatment ponds of the Presidente Médici coal-fired thermoelectric power plant, also exhibited good tolerance to high $\mathrm{CO}_{2}$ contents $[43,118]$.

In terms of carbon savings, the use o microalgae for biodiesel can lower considerably the $\mathrm{CO}_{2}$ emissions because the $\mathrm{CO}_{2}$ released on combustion should equal the $\mathrm{CO}_{2}$ fixed during plant or algal photosynthesis and growth. This will also depend upon the process to convert biomass to biodiesel. Generally, the more energy intensive the process, the greater the $\mathrm{CO}_{2}$ emitted over the fuel life cycle, assuming that this energy will be derived from fossil fuel.

\subsubsection{Wastewater nitrogen and phosphorous as microalgae nutrients}

Aquaculture systems involving microalgae production and wastewater treatment (e.g. of amino acids, enzyme, or food industries wastewaters) seems to be quite promising for microalgae growth combined with biological cleaning. This allows nutrition of microalgae by using organic compounds (nitrogen and phosphorous) available in some manufactures wastewater, not containing heavy metals and radioisotopes. Additionally, microalgae can mitigate the effects of sewage effluent and industrial sources of nitrogenous waste such as those originating from water treatment or fish aquaculture and at the same time contributing to biodiversity. Moreover, removing nitrogen and carbon from water, microalgae can help reduce the eutrophication in the aquatic environment.

Aslan and Kapdan [18] used C. vulgaris for nitrogen and phosphorus removal from wastewater with an average removal efficiency of $72 \%$ for nitrogen and $28 \%$ for phosphorus (from 3 to $8 \mathrm{mg} / \mathrm{L} \mathrm{NH}^{4+}$ and $1.5-3.5 \mathrm{mg} / \mathrm{LPO}_{4}{ }^{-3}$ ). Other widely used microalgae cultures for nutrient removal are Chlorella $[119,120]$, Scenedesmus [121], and Spirulina species [122]. Nutrient removal capacities of Nannochloris [123], Botryococcus brauinii [124], and cyanobacterium Phormidium bohneri $[125,126]$ have also been investigated.

\subsection{Microalgae fine chemicals and bioactive compounds}

Depending on the microalgae species various high-value chemical compounds may be extracted such as pigments, antioxidants, $\beta$-carotenes, polysaccharides, triglycerides, fatty acids, vitamins, and biomass, which are largely used as bulk commodities in different industrial sectors (e.g. pharmaceuticals, cosmetics, nutraceuticals, functional foods, biofuels). Also, algal hydrocolloids alginate, agar, and carrageenan are produced from seaweeds (especially macroalgae) and largely used as viscositymodifying agents in foods and pharmaceuticals [127]. Because the production of these fine chemicals and bioactive compounds normally demands the use of monocultures and controlled cultivation systems for a highest productivity and production efficiency, this has led to the development of large-scale PBRs.

\subsubsection{Microalgae applications in human health}

Consumers are progressively more concerned about debilitating illnesses (e.g. cholesterol, heart disease, osteoporosis, and cancer) and are not just relying on prescription medications to treat or prevent these illnesses, but increasingly examining the link between their diet and health.

Traditionally nutritional supplements derived from plants have been used and predominated in the market. Nevertheless, the health benefits of aquatic microorganisms such as algae are being investigated and more recognized and appreciated, within the last three to four decades, especially since the introduction of probiotic supplements [127]. Microalgae are viewed as having a protein quality value greater than other vegetable sources, for example, wheat, rice, and legumes, but poorer than animal sources, for example, milk and meat.

Microalgae have been found to contain several different types of sterols, including clionasterol isolated from Spirulina sp. that has been shown to increase the production of plaminogen-activating factor in vascular endothelial cells and thus facilitate cardiovascular disease prevention [127]. Additionally, several antioxidant compounds (e.g. dimethylsulfoniopropionate, mycosporines or mycosporinelike amino acids, $\beta$-carotene, astaxanthin and other carotenoids) have been isolated from microalgal sources, having the potential to protect against oxidative stress, cause of a wide spectrum of diseases and ageing.

Muriellopsis sp. among other microalgae is able to accumulate high levels of carotenoids such as lutein (normally presented in dark, leafy green vegetables, such as spinach and kale, as well as in corn, egg yolk, and some other foods with yellow color) that is used for the prevention and treatment of degenerative diseases [104].

Spirulina (Arthrospira) and Chlorella (a unicellular green microalga) are both considered edible algae that have been widely studied both in terms of their component molecules and their biological activities [40].

S. platensis and Spirulina maxima are the most popular, in terms of human consumption. Spirulina sp. is currently largely cultivated for use as a healthy food, since it boosts the immune system, helping to prevent both viral infection and cancer. It has also been reported to increase the number of lactic acid bacteria in the gastrointestinal tract as a result of a dietary supplement for promoting healthy hormonal balance in adult human. Additionally, it has a high nutritional value due to its protein content of $55-70 \%$ of total dry weight. For this reason Spirulina have been used as a food source in Asia for more than 1000 years and in Lake Texcoco (Mexico), during the Aztec civilization, some 700 years ago (e.g. dried and sold as small cakes to incorporate in bread) [127].

As stated by Barrow and Shahidi [127] Chlorella sp. presents several health benefits, when their extracts are ingested. For example, it can increase hemoglobin concentrations, lower blood sugar levels and act as hypocholesterolemic and hepatoprotective agents during malnutrition and ethionine intoxication.

Polysaccharide complexes from Chlorella pyrenoidosa and possibly Chlorella ellipsoidea contain glucose and any combination of galactose, rhamnose, mannose, arabinose, $\mathrm{N}$-acetyl glucosamide and $\mathrm{N}$-acetyl galactosamine [127]. These complexes are believed to have immunomodulating properties, specifically immune stimulatory activity and can inhibit the proliferation of Listeria monocytogenes and Candida albicans. Also, chlorella extracts may be administered to mammals, to increase the proliferation of splenocytes and production of cytokines, and can be used as a supplement to further stimulate their immune response [127].

Barrow and Shahidi [127] also refer that around years 1942 and 1946, a plankton soup primarily consisting of Chlorella sp. cells was used as a dietary aid for leprosy patients, showing increases in their energy, weight and health. Based on C. ellipsoidea, Japanese researchers have developed several trial food products (e.g. powdered green tea, soups, noodles, bread and rolls, cookies, ice cream, and soy sauce). 
Scenedesmus sp. was also previously investigated as a nutritional food source. Yet, their production at a commercial scale remains limited or underdeveloped. In general, their extracts are considered to be an acceptable candidate for incorporation into commonly used foods such as desserts, fruit puddings, ravioli, noodles, and soups. In 1961, human feeding studies showed similar acceptable levels of Scenedesmus sp. and Chlorella extracts for human consumption [127].

Dunaliella sp. (especially D. salina) has become popular as foodgrade green microalgae. In particular, due to their lipids and protein contents, glycerol concentration, $\beta$-carotene content (up to $4 \%$ of dry weight) and their exceptional ability to grow under brackish conditions [127]. These microalgae are currently being cultivated by several companies, in both Israel and Australia, as sources of these compounds and as dietary supplements and powders, containing vitamins A and C [128]. Furthermore, it has been postulated that the carotenoids found in Spirulina sp. and Dunaliella sp. may be more potent anticancer agents than $\beta$ carotene [104,105].

Long-chain polyunsaturated fatty acids (PUFAs), especially of $\omega 3$ and $\omega 6$ series such as eicosapentaenoic (EPA), docosahexaenoic (DHA), and arachidonic (AA) are considered pharmacologically important for dietetics and therapeutics [40]. They have been used for prophylactic and therapeutic treatment of chronic inflammations (e.g. rheumatism, skin diseases, and inflammation of the mucosa of the gastrointestinal tract). Also, they are believed to have a positive effect on cardio-circulatory diseases, coronary heart diseases, atherosclerosis, hypertension, cholesterol, and cancer treatment [127].

Microalgae such as N. oculata, Phaeodactylum tricornutum, and Thalassiosira pseudonana are able to produce PUFA with amounts varying, not only between species, but also during the various growth phases. A much higher percentage of the total cellular EPA was partitioned to triacylglycerols (TAGs) in stationary phase cells of $N$. oculata compared to P. tricornutum, while T. pseudonana produce EPA and DHA and partitioned these to TAGs during the stationary growth phase [127]. Besides, $\mathrm{CO}_{2}$ increase within photoautotrophic culture and induction of heterotrophic growth in these organisms, allow the increase and variation in PUFA composition of respectively Nannochloropsis sp. and C. cohnii [127].

Astaxanthin produced from $\mathrm{H}$. pluvialis (1.5-3\% of dry weight) is a high-value carotenoid, being very good at protecting membranous phospholipids and other lipids against peroxidation. The U.S. FDA for marketing has cleared $H$. pluvialis as a dietary supplement and it has been also approved in several European countries for human consumption. Preclinical studies suggested several health benefits for consuming astaxanthin such as [127]: immune-modulating functions (e.g. antibody production, antitumor activity); anticancer activity (inhibit cancer formation and growth in colon, bladder, liver, mammary, and oral cavity); photoprotection (e.g. from ultraviolet light); anti-inflammatory (e.g. for asthma, ulcers, anti muscle damage, providing increased muscle endurance); cardiovascular health (e.g. lower the risk for atherosclerosis); reduce risk for neurodegenerative diseases (e.g. Parkinson's and Alzheimer's dementia); protect the eye retina from oxidative damage and has an effect against agerelated macular disease.

\subsubsection{Microalgae for aquaculture and animal feed}

Considerable efforts have been made to promote the microalgae use in human food. However, high production costs and fear of toxicological contamination have limited algae application to expensive "healthy" foods. So far, microalgae culture have been more successful for food source and feed additive in the commercial rearing of many aquatic animals (e.g. rearing larvae and juveniles of many commercially important mollusks, penaeid prawn larvae, crustaceans and fish) both freshwater and marine.

Microalgae can also be used for culturing several types of zooplankton (rotifers, cladocerans, brine shrimp or copepods) used as live food in crustacean and finfish farming [89,128,129]. Isochrysis galbana and Tetraselmis suecica are considered the best food for larval bivalves, growing much better in unfiltered seawater to which these algae have been added. Drum-fried Scenedesmus can be used as Artemia food and Chlorella (marine, freshwater, or dried) is well suited for the rotifer Brachionus plicatilis cultivation but not for clams or oysters [89].

Although nutritional requirements for some consumer species have been defined, no set of nutritional criteria have yet been advanced. Generally, the algae must be non-toxic, in an acceptable size for ingestion, the cell wall should be digestible, and with sufficient biochemical constituents. Lipids quality rather than quantity is of prime importance to the nutritional value of microalgae. Depending on the amount of essential fatty acids (especially of the $\omega 6$ and $\omega 3$ groups) the fish larvae are either healthy or malformed [89].

Two distinct ways of growing microalgae for aquaculture applications can be distinguished $[89,129]$ :

(1) Natural populations of phytoplankton, either as they are found in nature or from cultures enriched by adding nutrients. The major drawbacks of using natural phytoplankton are the lack of control over production, consumption by undesirable predators, and contaminations by other species better adapted to existing environmental conditions, available nutrients, and algal populations composition.

(2) Algal monocultures, for example when it is required a high quality feed source with known nutritional properties or bacteria free algal cultures with reduced risk of introducing unwanted pathogens into animal cultures. The major difficulty, especially with large-scale monocultures, is that microalgae are susceptible to infection by viruses, bacteria, or fungi, and are exposed to predators such as protozoan, rotifers, crustaceans, and even microplantonic larvae of benthic organisms. As collapse of microalgae cultures owing to predation is very unpredictable in many aquaculture operations it is common practice to maintain cultures in duplicate.

Most problems with marine microalgae cultures are related to predation by various types of protozoans (e.g. zooflagellates, ciliates, and rhizopods). Other problem is the blooming of unwanted or toxic species such as the blue-green algae or dinoflagellates (red tides) that can result in high toxicity for consumers and even for humans. Examples are the massive development of green chlorococcalean algae, such as Synechocystis in freshwater, and also the development of Phaeodactylum in seawater that is undesirable for bivalve molluscs. [89]. A more controlled but more difficult approach consists of inducing and managing algal blooms completely separated from their consumers, i.e. first it is induced a bloom of natural phytoplankton and then, the consumers are introduced [89]. Also cultured microalgae can be used directly while alive or indirectly in a concentrated form after harvesting and preserving (e.g. as additives in pelleted food).

The most promising source of natural astaxanthin is $H$. pluvialis that synthesizes it from $\beta$-carotenes and accumulates it in oil droplets. This involves the action of enzymes presented in these lipid vesicles, supporting the suggestion that $\beta$-carotenes might be transported from the chloroplast to the lipid vesicles where the pigment is transformed into astaxanthin. Normally, astaxanthin is found either esterified with fatty acids or conjugated to proteins since its free form is very sensitive to oxidation. Currently, the largest market for astaxanthin is probably salmon and trout that 
are farmed and fed artificial diets [104]. Other animals, such shrimp, prawns, and chickens also benefit from astaxanthin supplementation in their diet (e.g. for exoskeleton and skin coloration, muscle, and yolk).

Although open pond systems can be used for the commercial production of $H$. pluvialis, it is normally done at large-scale PBR where two production phases can be better induced and managed: one first phase of fast growth to produce large quantities of green biomass under conditions of nutrient sufficiency, light, $\mathrm{pH}$, and temperature control, and a second phase where stresses are induced (e.g. through nutrients decrease, acetate, Fe, salt, temperature, etc.) to stimulate astaxanthin accumulation. In the second phase the reddening $H$. pluvialis cells lose their flagella and become significantly larger, heavier, and denser than average (up to $50 \mu \mathrm{m}$ versus $10-15 \mu \mathrm{m}$ for the green flagellates), which facilitates its harvesting by gravitational settling and centrifugation [126].

\section{Conclusions}

Current efforts and business investment are driving attention and marketing efforts on the promises of producing algal biodiesel and superior production systems.

A large number of companies are claiming that they are at the forefront of the technology and will be producing algal biodiesel economically within the next few years. However most of these companies have limited technical expertise and few have actually made biodiesel from algae.

Producing algal biodiesel requires large-scale cultivation and harvesting systems, with the challenging of reducing the cost per unit area. At a large scale, the algal growth conditions need to be carefully controlled and optimum nurturing environment have to be provided. Such processes are most economical when combined with sequestration of $\mathrm{CO}_{2}$ from flue gas emissions, with wastewater remediation processes, and/or with the extraction of high value compounds for application in other process industries.

Current limitations to a more widespread utilization of this feedstock for biodiesel production concern the optimization of the microalgae harvesting, oil extraction processes, and supply of $\mathrm{CO}_{2}$ for a high efficiency of microalgae production. Also, light, nutrients, temperature, turbulence, $\mathrm{CO}_{2}$ and $\mathrm{O}_{2}$ levels need to be adjusted carefully to provide optimum conditions for oil content and biomass yield.

It is therefore clear that a considerable investment in technological development and technical expertise is still needed before algal biodiesel is economically viable and can become a reality. This should be accomplished together with strategic planning and political and economic support.

Further efforts on microalgae production should concentrate in reducing costs in small-scale and large-scale systems. This can be achieved for example by using cheap sources of $\mathrm{CO}_{2}$ for culture enrichment (e.g. from a flue gas), use of nutrient-rich wastewaters, or inexpensive fertilizers, use of cheaper design culture systems with automated process control and with fewer manual labor, use of greenhouses and heated effluents to increase algal yields.

Apart from saving costs of raw-materials (nutrients and fresh water use), these measures will help to reduce GHG emissions, waste amount, and the feed cost by using of nitrogen fertilizers. Also, will raise the availability of microalgae biomass for different applications (e.g. food, agriculture, medicine, and biofuels, among others) and will contribute to the sustainability and market competitiveness of the microalgae industry.

\section{References}

[1] European Environmental Agency (EEA). Greenhouse gas emission trends and projections in Europe 2004: progress by the EU and its Member States towards achieving their Kyoto Protocol targets. Report $\mathrm{N}^{\circ}$. Copenhagen, Denmark; 2004

[2] European Environmental Agency (EEA). Greenhouse gas emission trends and projections in Europe 2007: tracking progress towards Kyoto targets. European Environmental Agency (EEA) Report $N^{\circ}$ 5. Copenhagen, Denmark; 2007.

[3] International Energy Agency (IEA). World Energy Outlook 2007. China and India Insights, Paris, France; 2007.

[4] Ormerod WG, Freund $\mathrm{P}$, Smith $\mathrm{A}$, Davison J. Ocean storage of $\mathrm{CO}_{2}$. IEA greenhouse gas R\&D programme. UK: International Energy Agency; 2002.

[5] Laherrere J. Forecasting production from discovery. In: ASPO; 2005.

[6] Dewulf J, Van Langenhove H. Renewables-based technology: sustainability assessment. John Wiley \& Sons, Ltd; 2006.

[7] Gilbert R, Perl A. Transport revolutions: moving people and freight without oil. Earthscan; 2008.

[8] COM (2006) 34 final. An EU strategy for biofuels. Commission of the European Communities, Brussels, 8.2.2006.

[9] Bozbas K. Biodiesel as an alternative motor fuel: production and policies in the European Union. Renewable and Sustainable Energy Reviews 2008;12: 542-52.

[10] Scarlat N, Dallemand JF, Pinilla FG. Impact on agricultural land resources of biofuels production and use in the European Union. In: Bioenergy: challenges and opportunities. International conference and exhibition on bioenergy; 2008.

[11] Renewable Fuel Agency (RFA). The Gallagher review of the indirect effects of biofuels production; 2008.

[12] Canakci M, Sanli H. Biodiesel production from various feedstocks and their effects on the fuel properties. Journal of Industrial Microbiology and Biotechnology 2008;35:431-41.

[13] Reinhardt G, Rettenmaier N, Köppen S. How sustainable are biofuels for transportation?In: Bioenergy: challenges and opportunities. International conference and exhibition on bioenergy; 2008.

[14] Li Y, Wang B, Wu N, Lan CQ. Effects of nitrogen sources on cell growth and lipid production of Neochloris oleoabundans. Applied Microbiology and Biotechnology 2008;81(4):629-36.

[15] Li Y, Horsman M, Wu N, Lan CQ, Dubois-Calero N. Biofuels from microalgae. Biotechnology Progress 2008;24(4):815-20.

[16] Richmond A. Handbook of microalgal culture: biotechnology and applied phycology. Blackwell Science Ltd; 2004.

[17] Sheehan J, Dunahay T, Benemann J, Roessler P. A look back at the U.S Department of Energy's aquatic species program: biodiesel from algae. NREL/TP-580-24190, National Renewable Energy Laboratory, USA; 1998.

[18] Aslan S, Kapdan IK. Batch kinetics of nitrogen and phosphorus removal from synthetic wastewater by algae. Ecological Engineering 2006;28(1): 64-70.

[19] Pratoomyot J, Srivilas P, Noiraksar T. Fatty acids composition of 10 microalgal species. Songklanakarin Journal of Science and Technology 2005;27(6): 1179-87.

[20] Renaud SM, Thinh LV, Parry DL. The gross chemical composition and fatty acid composition of 18 species of tropical Australian microalgae for possible use in mariculture. Aquaculture 1999:170:147-59.

[21] Chisti Y. Biodiesel from microalgae. Biotechnology Advances 2007;25(3): 294-306.

[22] Hossain ABMS, Salleh A, Boyce AN, Chowdhury P, Naqiuddin M. Biodiesel fuel production from algae as renewable energy. American Journal of Biochemistry and Biotechnology 2008;4(3):250-4.

[23] Hu Q, Sommerfeld M, Jarvis E, Ghirardi M, Posewitz M, Seibert M, et al. Microalgal triacylglycerols as feedstocks for biofuels production: perspectives and advances. The Plant Journal 2008;54:621-39.

[24] Rodolfi L, Zittelli GC, Bassi N, Padovani G, Biondi N, Bonini G, et al. Microalgae for oil: strain selection, induction of lipid synthesis and outdoor mass cultivation in a low-cost photobioreactor. Biotechnology and Bioengineering 2009;102(1):100-12.

[25] Rosenberg JN, Oyler GA, Wilkinson L, Betenbaugh MJ. A green light for engineered algae: redirecting metabolism to fuel a biotechnology revolution. Current Opinion in Biotechnology 2008;19(5):430-6.

[26] Schenk PM, Hall SRT, Stephens E, Marx UC, Mussgnug JH, Posten C, et al. Second generation biofuels: high-efficiency microalgae for biodiesel production. Bioenergy Research 2008;1:20-43.

[27] Tsukahara K, Sawayama S. Liquid fuel production using microalgae. Journal of the Japan Petroleum Institute 2005;48(5):251-9.

[28] Delucchi MA. A Lifecycle Emissions Model (LEM): lifecycle emissions from transportation fuels; motor vehicles, transportation modes, electricity use, heating and cooking fuels. Main report UCD-ITS-RR-03-17; 2003.

[29] Wang B, Li Y, Wu N, Lan CQ. $\mathrm{CO}_{2}$ bio-mitigation using microalgae. Applied Microbiology and Biotechnology 2008;79(5):707-18.

[30] Directive 2003/30/EC on the promotion of the use of biofuels or other renewable fuels for transport; May 8, 2003.

[31] Raja R, Hemaiswarya S, Kumar NA, Sridhar S, Rengasamy R. A perspective on the biotechnological potential of microalgae. Critical Reviews in Microbiology $2008 ; 34(2): 77-88$.

[32] Spolaore P, Joannis-Cassan C, Duran E, Isambert A. Commercial applications of microalgae. Journal of Bioscience and Bioengineering 2006;101(2): 87-96.

[33] Barclay WR. Mixtures of omega-3 and omega-6 highly unsaturated fatty acids from euryhaline microorganisms. US Patent 6977167; 2005. 
[34] Behrens PW, Thompson JM, Apt K, Pfeifer JW, Wynn JP, Lippmeier C, et al. Production of high levels of DHA in microalgae using modified amounts of chloride and potassium. US Patent 7163811; 2007.

[35] Kanel JS, Guelcher SA. Method for rupturing microalgae cells. US Patent 6000551; 1999.

[36] European Commission. The impact of a minimum 10\% obligation for biofuel use in the EU-27 in 2020 on agricultural markets, impact assessment renewable energy roadmap. European Commission (EC), Directorate-General For Agriculture and Rural Development; March 2007.

[37] Torrey M. Algae in the tank. International News on Fats Oils and Related Materials 2008;19(7):432-7

[38] Bijl HL, Wolf JH, Schaap A, Visser JMJ. Preparation of microbial polyunsaturated fatty acid containing oil from pasteurised biomass. US Patent 6727373; 2004.

[39] Yokochi T, Nakahara T, Higashihara T, Tanaka S, Yaguchi T. Microorganisms capable of producing highly unsaturated fatty acids and process for producing highly unsaturated fatty acids by using the microorganisms. US Patent 6582941; 2003.

[40] Pulz O, Gross W. Valuable products from biotechnology of microalgae. Applied Microbiology and Biotechnology 2004;65(6):635-48.

[41] Barclay B. Microalgae Culture Collection 1984-1985. Microalgal Technology Research Group (MTRG). SERI/SP-231-2486; 1984.

[42] Chiu SY, Kao CY, Tsai MT, Ong SC, Chen $\mathrm{CH}$, Lin CS. Lipid accumulation and $\mathrm{CO}_{2}$ utilization of Nannochloropsis oculata in response to $\mathrm{CO}_{2}$ aeration. Bioresource Technology 2009;100:833-8.

[43] De Morais MG, Costa JAV. Carbon dioxide fixation by Chlorella kessleri, $C$. vulgaris, Scenedesmus obliquus and Spirulina sp. cultivated in flasks and vertical tubular photobioreactors. Biotechnology Letters 2007;29(9):1349-52.

[44] Demirbas A. Progress and recent trends in biodiesel fuels. Energy Conversion and Management 2009;50:14-34.

[45] Eriksen NT. The technology of microalgal culturing. Biotechnology Letters 2008;30:1525-36

[46] Feinberg DA. Fuel options from microalgae with representative chemical compositions. SERI/TR-231-2427; 1984.

[47] Gouveia L, Oliveira AC. Microalgae as a raw material for biofuels production. Journal of Industrial Microbiology and Biotechnology 2009;36:269-74.

[48] Grima EM, Fernández FGA, Camacho FG, Rubio FC, Chisti Y. Scale-up of tubular photobioreactors. Journal of Applied Phycology 2000;12: 355-68.

[49] Huntley ME, Redalje DG. $\mathrm{CO}_{2}$ mitigation and renewable oil from photosynthetic microbes: a new appraisal. Mitigation and Adaptation Strategies for Global Change 2007;12(4):573-608.

[50] Illman AM, Scragg AH, Shales SW. Increase in Chlorella strains calorific values when grown in low nitrogen medium. Enzyme and Microbial Technology 2000;27:631-5.

[51] Leathers J, Celina M, Chianelli R, Thoma S, Gupta V. Systems analysis and futuristic designs of advanced biofuel factory, concepts. SANDIA Report, SAND2007-6872; 2007.

[52] Lee YK. Microalgal mass culture systems and methods: their limitation and potential. Journal of Applied Phycology 2001;13:307-15

[53] Sancho MEM, Castillo JMJ, El Yousfi F. Photoautotrophic consumption of phosphorus by Scenedesmus obliquus in a continuous culture. Influence of light intensity. Process Biochemistry 1999;34(8):811-8.

[54] Miao X, Wu Q. Biodiesel production from heterotrophic microalgal oil. Bioresource Technology 2006;97(6):841-6.

[55] Michiki $\mathrm{H}$. Biological $\mathrm{CO}_{2}$ fixation and utilization project. Energy Conversion and Management 1995;36(6-9):701-5.

[56] Minowa R, Yokoyama S, Kishimoto M, Okakurat T. Oil production from algal cells of Dunaliella tertiolecta by direct thermochemical liquefaction. Fuel 1995;74(12):1735-8.

[57] Moheimani NR. The culture of Coccolithophorid Algae for carbon dioxide bioremediation. PhD thesis. Murdoch University; 2005

[58] Moheimani NR, Borowitzka MA. The long-term culture of the coccolithophore Pleurochrysis carterae (Haptophyta) in outdoor raceway ponds. Journal of Applied Phycology 2006;18:703-12.

[59] Natrah F, Yoso VFM, Shari VM, Abas F, Mariana NS. Screening of Malaysian indigenous microalgae for antioxidant properties and nutritional value. Journal of Applied Phycology 2007;19:711-8.

[60] Negoro M, Shioji N, Miyamoto K, Miura Y. Growth of microalgae in high $\mathrm{CO}_{2}$ gas and effects of $\mathrm{SO}_{X}$ and $\mathrm{NO}_{X}$. Applied Biochemistry and Biotechnology - Part A Enzyme Engineering and Biotechnology 1991;28-29:87786.

[61] Peng W, Wu Q, Tu P, Zhao N. Pyrolitic characteristics of microalgae as renewable energy source determined by thermogravimetric analysis. Bioresource Technology 2001;80:1-7.

[62] Poisson L, Devos M, Pencreac'h G, Ergan F. Benefits and current developments of polyunsaturated fatty acids from microalgae lipids. OCL - Oleagineux Corps Gras Lipides 2002;9(2-3):92-5.

[63] Sawayama S, Minowa T, Yokoyama SY. Possibility of renewable energy production and $\mathrm{CO}_{2}$ mitigation by thermochemical liquefaction of microalgae. Biomass and Bioenergy 1999;17(1):33-9.

[64] Scragg AH, Illman AM, Carden A, Shales SW. Growth of microalgae with increased calorific values in a tubular bioreactor. Biomass and Bioenergy 2002;23(1):67-73.

[65] Teixeira CM, Morales ME. Microalga como matéria-prima para a produção de biodiesel. Revista: Biodiesel o Novo combustível do Brasil; 2007. pp. 91-6.
[66] Thomas WH, Tornabene TG, Weissman J. Screening for lipid yielding microalgae: activities for 1983. SERI/STR-231-2207; 1984

[67] Ugwu CU, Aoyagi H, Uchiyama H. Photobioreactors for mass cultivation of algae. Bioresource Technology 2008;99(10):4021-8.

[68] Zhu CJ, Lee YK. Determination of biomass dry weight of marine microalgae. Journal of Applied Phycology 1997;9:189-94.

[69] Ötles S, Pire R. Fatty acid composition of Chlorella and Spirulina microalgae species. Journal of AOAC International 2001;84(6):1708-14.

[70] Kheira AAA, Atta NMM. Response of Jatropha curcas L. to water deficit: yield, water use efficiency and oilseed characteristics. Biomass and Bioenergy; in press. doi:10.1016/j.biombioe.2008.05.015.

[71] Callaway JC. Hempseed as a nutritional resource: an overview. Euphytica 2004; 140:65-72.

[72] Hili AM, Feinberg DA. Fuel from microalgae: lipid products, energy from biomass: building on a generic technology base. In: Second technical review meeting; 1984.

[73] Kulay LA, Silva GA. Comparative screening LCA of agricultural stages of soy and castor beans. In: 2nd international conference on life cycle management - LCM2005; 2005. pp. 5-7.

[74] Mobius BioFuels. What is biodiesel? Mobius Biofuels, LLC; 2008. Accessed in December at: http://www.mobiusbiofuels.com/biodiesel.htm.

[75] Nielsen DC. Oilseed productivity under varying water availability. In: Proceedings of 20th annual central plains irrigation conference and exposition; 2008. pp. 30-33.

[76] Peterson CL, Hustrulid T. Carbon cycle for rapeseed oil biodiesel fuels. Biomass and Bioenergy 1998;14(2):91-101.

[77] Rathbauer J, Prankl H, Krammer K. Energetic use of natural vegetable oil in Austria. Austria: BLT - Federal Institute of Agricultural Engineering; 2002.

[78] Reijnders L, Huijbregts MAJ. Biogenic greenhouse gas emissions linked to the life cycles of biodiesel derived from European rapeseed and Brazilian soybeans. Journal of Cleaner Production 2008;16:1943-8.

[79] Vollmann J, Moritz T, Karg C, Baumgartner S, Wagentrist H. Agronomic evaluation of camelina genotypes selected for seed quality characteristics. Industrial Crops and Products 2007;26:270-7.

[80] Zappi M, Hernandez R, Sparks D, Horne J, Brough M, Swalm DC, et al. A review of the engineering aspects of the biodiesel industry. MSU E-TECH Laboratory Report ET-03-003; 2003.

[81] Bahadur NP, Boocock DGB, Konar SK. Liquid hydrocarbons from catalytic pyrolysis of sewage sludge lipid and canola oil: evaluation of fuel properties. Energy Fuels 1995;9:248-56.

[82] Babu BV. Biomass pyrolysis: a state-of-the-art review. Biofuels Bioproducts Biorefinin 2008;2(5):393-414.

[83] Boateng AA, Mullen CA, Goldberg N, Hicks KB, Jung HJG, Lamb JFS. Production of bio-oil from alfalfa stems by fluidized-bed fast pyrolysis. Industrial and Engineering Chemistry Research 2008;47:4115-22.

[84] Maxwell EL, Folger AG, Hogg SE. Resource evaluation and site selection for microalgae production systems. SERI/TR-215-2484; May 1985.

[85] Gressel J. Transgenics are imperative for biofuel crops. Plant Science 2008;174(3):246-63.

[86] Kaewpintong K. Cultivation of Haematococcus pluvialis in Airlift Bioreactor. Master thesis in Chemical Engineering. Department of Chemical Engineering, Faculty of Engineering, Chulalongkorn University; 2004.

[87] Chojnacka K, Marquez-Rocha FJ, Kinetic. Stoichiometric relationships of the energy and carbon metabolism in the culture of microalgae. Biotechnology 2004;3(1):21-34

[88] Williams JA. Keys to Bioreactor selection. CEP Magazine 2002;34-41.

[89] De Pauw N, Morales J, Persoone G. Mass culture of microalgae in aquaculture systems: progress and constraints. Hydrobiologia 1984;116/117: 121-34.

[90] Barbosa MJGV. Microalgal photobioreactors: scale-up and optimisation. PhD thesis. Wageningen University, The Netherlands; 2003.

[91] Weissman JC, Goebel RP. Design and analysis of microalgal open pond systems for the purpose of producing fuels: a subcontract report. US DOESERI; 1987.

[92] Liu ZY, Wang GC, Zhou BC. Effect of iron on growth and lipid accumulation in Chlorella vulgaris. Bioresource Technology 2008;99:4717-22.

[93] Macedo RVT, Alegre RM. Influência do Teor de Nitrogênio no Cultivo de Spirulina Maxima em Dois Níveis de Temperatura - Parte II. Produção de Lipídios Ciênc Tecnol Aliment Campinas 2001;21(2):183-6.

[94] Grima ME, Belarbi EH, Fernandez FGA, Medina AR, Chisti Y. Recovery of microalgal biomass and metabolites: process options and economics. Biotechnology Advances 2003;20(7-8):491-515.

[95] Cravotto G, Boffa L, Mantegna S, Perego P, Avogadro M, Cintas P. Improved extraction of vegetable oils under high-intensity ultrasound and/or microwaves. Ultrasonics Sonochemistry 2008;15(5):898-902.

[96] Warabi Y, Kusdiana D, Saka S. Reactivity of triglycerides and fatty acids of rapeseed oil in supercritical alcohols. Bioresource Technology 2004;91(3): 283-7.

[97] Azcan N, Danisman A. Microwave assisted transesterification of rapeseed oil. Fuel 2008;87:1781-8.

[98] Gogate PR. Cavitational reactors for process intensification of chemical processing applications: a critical review. Chemical Engineering and Processing 2008;47:515-27.

[99] Gogate PR, Kabadi AM. A review of applications of cavitation in biochemical engineering/biotechnology. Biochemical Engineering Journal 2009;44: 60-72. 
[100] Kalva A, Sivasankar T, Moholkar VS. Physical mechanism of ultrasoundassisted synthesis of biodiesel. Industrial and Engineering Chemistry Research 2008;48(1):534-44.

[101] Deshmane VG, Gogate PR, Pandit AB. Ultrasound-assisted synthesis of biodiesel from palm fatty acid distillate. Industrial and Engineering Chemistry Research; in press.

[102] Borowitzka MA. Commercial production of microalgae: ponds, tanks, tubes and fermenters. Journal of Biotechnology 1999;70(1-3):313-21.

[103] Chen F. High cell density culture of microalgae in heterotrophic growth. Tibtech 1996;14:421-6.

[104] Del Campo JA, García-González M, Guerrero MG. Outdoor cultivation of microalgae for carotenoid production: current state and perspectives. Applied Microbiology and Biotechnology 2007;74:1163-74

[105] Canela APRF, Rosa PTV, Marques MOM, Meireles MAA. Supercritical fluid extraction of fatty acids and carotenoids from the microalgae Spirulina maxima. Industrial and Engineering Chemistry Research 2002;41(12): 3012-8.

[106] Piccolo T. Aquatic biofuels. GlobeFish-FIIU; May 2008, Available at: http:// www.globefish.org/files/Aquaticbiofuels_638.pdf.

[107] Bilanovic D, Andargatchew A, Kroeger T, Shelef G. Freshwater and marine microalgae sequestering of $\mathrm{CO}_{2}$ at different $\mathrm{C}$ and $\mathrm{N}$ concentrationsresponse surface methodology analysis. Energy Conversion and Management 2009:50:262-7.

[108] Hodaifa G, Martìnez ME, Sànchez S. Use of industrial wastewater from oliveoil extraction for biomass production of Scenedesmus obliquus. Bioresource Technology 2008;99(5):1111-7.

[109] Jacob-Lopes E, Lacerda LMCF, Franco TT. Biomass production and carbon dioxide fixation by Aphanothece microscopica Nägeli in a bubble column photobioreactor. Biochemical Engineering Journal 2008;40(1):27-34.

[110] Jacob-Lopes E, Scoparo CHG, Lacerda LMCF, Franco TT. Effect of light cycles (night/day) on $\mathrm{CO}_{2}$ fixation and biomass production by microalgae in photobioreactors. Chemical Engineering and Processing 2009;48(1): 306-10.

[111] Murakami M, Yamada F, Nishide T, Muranaka T, Yamaguchi N, Takimoto Y. The biological $\mathrm{CO}_{2}$ fixation using Chlorella sp. with high capability in fixing $\mathrm{CO}_{2}$. Studies in Surface Science and Catalysis 1998;114:315-20.

[112] Kadam KL. Power plant flue gas as a source of $\mathrm{CO}_{2}$ for Microalgae cultivation: economic impact of different process options. Energy Conversion and Management 1997;38(Suppl.):505-10.

[113] Kadam KL. Microalgae production from power plant flue gas: environmental implications on a life cycle basis. NREL/TP-510-29417. Colorado, USA: National Renewable Energy Laboratory; 2001.

[114] Maeda K, Owada M, Kimura N, Omata K, Karube I. $\mathrm{CO}_{2}$ fixation from the flue gas on coal-fired thermal power plant by microalgae. Energy Conversion and Management 1995;36(6-9):717-20.
[115] Zeiler KG, Heacox DA, Toon ST, Kadam KL, Brown LM. Use of microalgae for assimilation and utilization of carbon dioxide from fossil fuel-fired power plant flue gas. Energy Conversion and Management 1995;36(6-9):707-12.

[116] Iwasaki I, Hu Q, Kurano N, Miyachi S. Effect of extremely high- $\mathrm{CO}_{2}$ stress on energy distribution between photosystem I and photosystem II in a 'high$\mathrm{CO}_{2}$ ' tolerant green alga. Chlorococcum littorale and the intolerant green alga Stichococcus bacillaris. Journal of Photochemistry and Photobiology 1998;B44:184-90.

[117] Sakai N, Sakamoto Y, Kishimoto N, Chihara M, Karube I. Chlorella strains from hot springs tolerant to high temperature and high $\mathrm{CO}_{2}$. Energy Conversion and Management 1995;36(6-9):693-6.

[118] De Morais MG, Costa JAV. Isolation and selection of microalgae from coa fired thermoelectric power plant for biofixation of carbon dioxide. Energy Conversion and Management 2007;48(7):2169-73.

[119] Gonzales LE, Canizares RO, Baena S. Efficiency of ammonia and phosphorus removal from a Colombian agroindustrial wastewater by the microalgae Chlorealla vulgaris and Scenedesmus dimorphus. Bioresource Technology 1997;60:259-62.

[120] Lee K, Lee CG. Effect of light/dark cycles on wastewater treatments by microalgae. Biotechnology and Bioprocess Engineering 2001;6:194-9.

[121] Martínez ME, Sánchez S, Jiménez JM, El Yousfi F, Muñoz L. Nitrogen and phosphorus removal from urban wastewater by the microalga Scenedesmus obliquus. Bioresource Technology 2000;73(3):263-72.

[122] Olguín EJ, Galicia S, Mercado G, Perez T. Annual productivity of Spirulina (Arthrospira) and nutrient removal in a pig wastewater recycle process under tropical conditions. Journal of Applied Phycology 2003;15:249-57.

[123] Jimenez-Perez MV, Sanches-Castillo P, Romera O, Fernandez-Moreno D, Perez-Martinez C. Growth and nutrient removal in free and immobilized planktonic green algae isolated from pig manure. Enzyme and Microbial Technology 2004;34:392-8.

[124] An JY, Sim SJ, Lee JS, Kim BK. Hydrocarbon production from secondarily treated piggery wastewater by the green algae, Botryococcus braunii. Journal of Applied Phycology 2003;15:185-91.

[125] Dumas A, Laliberte G, Lessard P, Noue J. Biotreatment of fish farm effluents using the cyanobacterium Phormidium bohneri. Aquaculture Engineering 1998;17:57-68.

[126] Laliberte G, Lessard P, Noue J, Sylvestre S. Effect of phosphorus addition on nutrient removal from wastewater with the cyanobacterium Phormidium bohneri. Bioresource Technology 1997;59:227-33.

[127] Barrow C, Shahidi F. Marine nutraceuticals and functional foods. CRC Press, Taylor \& Francis Group; 2008.

[128] Brown MR, Jeffrey SW, Volkman JK, Dunstan GA. Nutritional properties of microalgae for mariculture. Aquaculture 1997;151(1-4):315-31.

[129] Borowitzka MA. Microalgae for aquaculture: opportunities and constraints. Journal of Applied Phycology 1997;9:393-401. 